2017-11-01

\title{
Highly Compressible Origami Bellows for Harsh Environments
}

Jared J. Butler

Brigham Young University

Follow this and additional works at: https://scholarsarchive.byu.edu/etd

Part of the Mechanical Engineering Commons

\section{BYU ScholarsArchive Citation}

Butler, Jared J., "Highly Compressible Origami Bellows for Harsh Environments" (2017). All Theses and Dissertations. 6657.

https://scholarsarchive.byu.edu/etd/6657

This Thesis is brought to you for free and open access by BYU ScholarsArchive. It has been accepted for inclusion in All Theses and Dissertations by an authorized administrator of BYU ScholarsArchive. For more information, please contact scholarsarchive@byu.edu, ellen_amatangelo@byu.edu. 
Highly Compressible Origami Bellows for Harsh Environments

Jared J. Butler

A thesis submitted to the faculty of

Brigham Young University

in partial fulfillment of the requirements for the degree of

Master of Science

Spencer P. Magleby, Chair

Larry L. Howell

Brian D. Jensen

Department of Mechanical Engineering

Brigham Young University

Copyright $\odot 2017$ Jared J. Butler

All Rights Reserved 


\author{
ABSTRACT \\ Highly Compressible Origami Bellows for Harsh Environments \\ Jared J. Butler \\ Department of Mechanical Engineering, BYU \\ Master of Science
}

The use of origami-based bellows is of interest in fields where traditional metal bellows are incapable of meeting compression, mass, or flexibility constraints. Metal bellows are often used in space applications but frequently complicate spacecraft design. Origami-based bellows capable of meeting design constraints while adequately shielding sensitive spacecraft parts may be advantageous to space mechanism design.

The design and testing of a highly compressible origami bellows for harsh environments is described. Several origami patterns were evaluated and the Kresling fold pattern was designed to meet constraints and selected for use in the bellows design. Origami bellows were prototyped in five different materials and tested in fatigue, thermal cycling, ablation, and radiation. Tested bellows show good fatigue life exceeding 100,000 cycles for some materials and resilience to potential harsh environmental conditions such as thermal cycling, abrasion, and high radiation. The bellows can be designed to fit within a given inner and outer diameter and stroke length depending on the design requirements. The origami bellows shows promise for space application and as an adequate replacement for current metal bellows due to its high compressibility and low mass.

The design, testing, and fabrication of an origami-based bellows for microgravity drilling is presented. The benefits of origami created an opportunity for application on NASA's Asteroid Redirect Mission (ARM) to protect sensitive parts from debris. Origami-based bellows were designed to fit spacial limitations and meet needed compression ratios. Designs have demonstrated high mass reductions, improved stroke length, greatly decreased stowed volume, improved flexibility, and reduced reaction forces in comparison with traditional metal bellows. Material and design testing demonstrated that a nylon-reinforced polyvinyl fluoride based bellows with an aramid fiber stitched seam is well suited for debris containment in space conditions. Various epoxies were able to maintain an adequate bond with polyvinyl fluoride below expected environmental temperature for bellows mounting to the ARM drill. Asymmetric compression of the bellows can occur at extreme low temperatures and is preventable by balancing stiffness within the structure.

Keywords: origami, bellows, space, asteroid, mars, compressible, debris 


\section{ACKNOWLEDGMENTS}

First and foremost, I would like to thank my wife Amy for her support during this research, including motivation, editing, revisions, and organization. I thank my children Adelyn and Bridger

for being excited about "daddy's space work." This work was made possible through foresight and trust offered to a then middle school teacher from Larry Howell and Spencer Magleby. I thank them for providing funding to pursue this work and obtain graduate credentials. I thank my mentor from NASA's Jet Propulsion Laboratory Aaron Parness for the opportunity to mature this work for space applications and for his guidance and professional advice. Additionally, I thank Brian Jensen for him mentoring.

I could not have accomplished this work without several students in the Compliant Mechanism Research Group, including Jason Dearden, Jared Bruton, and Ezekiel Merriam. Their assistance in editing and consultation enabled the success of this work.

For the research in Chapter 2, I thank my co-authors Jessica Morgan, Kyler Tolman, Nathan Pehrson, Terri Bateman, Spencer Magleby, and Larry Howell for aiding in various aspects of the work. I thank Charles Dandino, Jonathan Sauder, and Brian Trease from NASA's Jet Propulsion Laboratory for assistance in this work, specifically in relation to Technology Readiness Level establishment during the maturation of this technology. For the research in Chapter 3, I thank my co-authors Aaron Parness, Stefano Mancini, Spencer Magleby, and Larry Howell. Additionally, I acknowledge Brett Kennedy, Matthew Shekels, Andrew Berg, and Andrew Willig from NASA's Jet Propulsion Laboratory for collaboration and ideation.

Research was carried out, in part, at the Jet Propulsion Laboratory, California Institute of Technology, under contract with the National Aeronautics and Space Administration. Government sponsorship is acknowledged. This material is also based on work supported by the National Science Foundation and the Air Force Office of Scientific Research under NSF Grant No. EFRIODISSEI-1240417. 


\section{TABLE OF CONTENTS}

LIST OF TABLES $\ldots \ldots \ldots \ldots \ldots \ldots \ldots \ldots \ldots \ldots \ldots$ vi

LIST OF FIGURES $\ldots \ldots \ldots \ldots \ldots \ldots \ldots \ldots$ vii

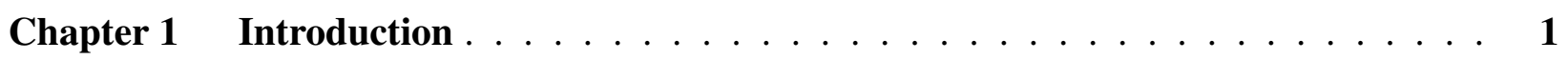

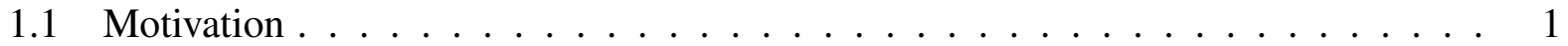

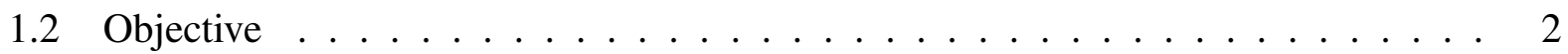

1.3 Thesis Outline . . . . . . . . . . . . . . . . . . 2

Chapter 2 Origami Bellows for Martian Environment $\ldots \ldots \ldots \ldots$

2.1 Introduction . . . . . . . . . . . . . . . . . . . 4

2.2 Design and Selection of Highly Compressible Origami Bellows for Harsh Envi-

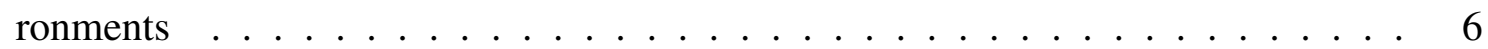

2.2.1 Possible Origami Fold Patterns . . . . . . . . . . . . . . . 6

2.2.2 Origami Bellows Pattern Design and Selection _ . . . . . . . . . . 8

2.2 .3 Materials . . . . . . . . . . . . . . . . . . . . . . 12

2.2 .4 Fabrication . . . . . . . . . . . . . . . . . . . . 13

2.3 Testing . . . . . . . . . . . . . . . . . . . . . . . . 14

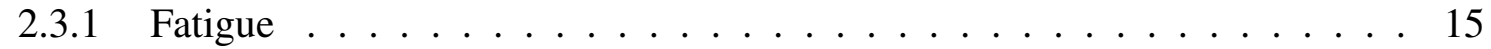

2.3.2 Thermal Cycling . . . . . . . . . . . . . . . . . . . 15

2.3.3 Ablation . . . . . . . . . . . . . . . . . . 17

2.3 .4 Radiation . . . . . . . . . . . . . . . . . . . . . . . . . 18

2.3.5 Full Prototype Testing . . . . . . . . . . . . . . . . . 20

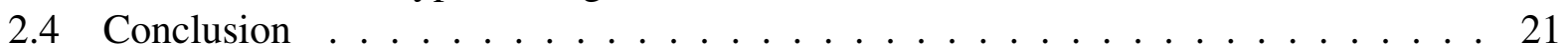

Chapter 3 Origami Bellows for Microgravity Drilling . . . . . . . . . . . . 23

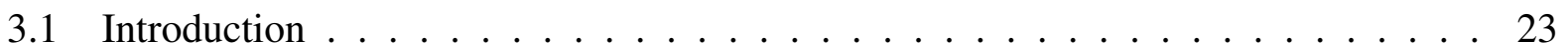

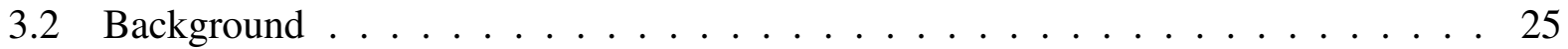

3.2.1 Modeling of Origami Bellows . . . . . . . . . . . . . . 26

3.2 .2 Prevention of Crease Inversion . . . . . . . . . . . . . . . . . 28

3.3 Bellows Design . . . . . . . . . . . . . . . . . . . . . . . . . . . . . . 29

3.3.1 Origami Designs . . . . . . . . . . . . . . . . . . . . . . . 29

3.3 .2 Materials . . . . . . . . . . . . . . . . . . . . 32

3.3.3 Seam Closure . . . . . . . . . . . . . . . . . . . . . . . . . . . . 33

3.4 Design Selection . . . . . . . . . . . . . . . . . . . . . . . . 35

3.4.1 Origami Design Selection . . . . . . . . . . . . . . . . 35

3.4 .2 Material Selection . . . . . . . . . . . . . . . . . . . 36

3.4 .3 Seam Testing and Selection _ . . . . . . . . . . . . . . . . 36

3.4 .4 Selected Design . . . . . . . . . . . . . . . . . . . . . . 37

3.5 Fabrication of Origami Bellows $\ldots \ldots \ldots \ldots$

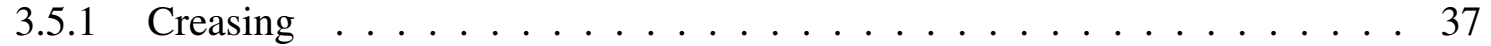

3.5.2 Epoxy Testing and Selection for Mounting . . . . . . . . . . . 38 
3.6 Environmental Testing . . . . . . . . . . . . . . . . . . . . . . . . . . 40

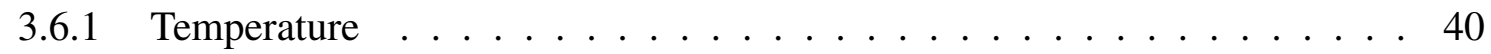

3.6 .2 Drilling . . . . . . . . . . . . . . . . 41

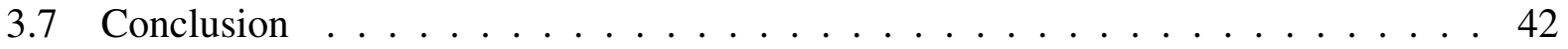

Chapter 4 Conclusion $\ldots \ldots \ldots \ldots \ldots \ldots \ldots \ldots$

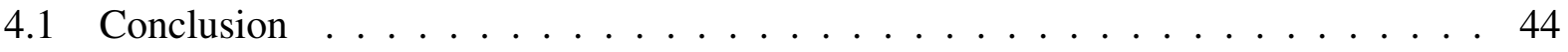

4.2 Future Work . . . . . . . . . . . . . . . . . . . . 45

REFERENCES . . . . . . . . . . . . . . . . . . . . . . . . . 47 


\section{LIST OF TABLES}

2.1 Comparison of Metal bellows, Accordion origami bellows, . . . . . . . . . . . . 10

2.2 Screening study of the origami bellows test results for harsh environments. The adhesive refers to both the Kapton ${ }^{\circledR}$ tape and 3M Transfer Tape. Note that this data 19

2.3 Results of full-size Kapton ${ }^{\circledR}$ prototype testing. . . . . . . . . . . . . . . 21

3.1 Summary of key design parameters for origami-based bellows. . . . . . . . . . . . 32

3.2 Summary of traditional and origami-based bellows features. . . . . . . . . . . . 42 


\section{LIST OF FIGURES}

2.1 A highly compressible bellows reduces the length of the drill shaft, thus reducing weight and cost in space applications. . . . . . . . . . . . . . 5

2.2 Possible origami models applicable to bellows. . . . . . . . . . . . . 6

2.3 (a) Kresling and (b) Accordion bellows patterns before and (c) after folding. . . . . 7

2.4 The Tachi-Miura Polyhedron. . . . . . . . . . . . . . . . . . . . 7

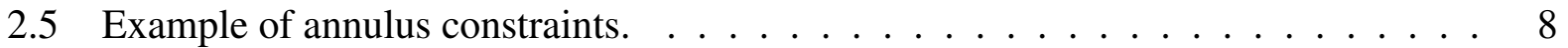

2.6 The tessellated Kresling pattern with $n=5$ and $s=2 \ldots \ldots \ldots$. . . . . . 8

2.7 The Kresling and Accordion tessellation units. . . . . . . . . . . . . . . 9

2.8 Single story Kresling showing the deployment angle, $\delta \ldots \ldots \ldots \ldots$

2.9 Materials tested in the Kresling fold pattern from left to right: Mylar $^{\circledR}$, Tyvek ${ }^{\circledR}$, Kapton $^{\circledR}$, UHMWPE, and ETFE. . . . . . . . . . . . . . . . . . . . . 13

2.10 Fatigue testing apparatus. . . . . . . . . . . . . . . . . . . 14

2.11 A bellows in the fatigue tester. . . . . . . . . . . . . . . . . . 15

2.12 Sandstorm simulation apparatus. . . . . . . . . . . . . . . . 17

2.13 UV simulation apparatus. . . . . . . . . . . . . . . . . . . . 18

2.14 Full-size Kapton ${ }^{\circledR}$ prototype. . . . . . . . . . . . . . . . . . . . . . . . . 20

2.15 Three full-size Kapton ${ }^{\circledR}$ prototypes under fatigue testing. Failure occuring on Bellows 2 at predicted fold. . . . . . . . . . . . . . . . . . 20

3.1 Microspine tool for the Asteroid Redirect Mission (ARM) _ . . . . . . . . . . . 24

3.2 Traditional metal bellows and the need to protect the inner ARM drill mechanisms from debris. . . . . . . . . . . . . . . . . . . . . . . . . . . . . . . 24

3.3 Increased compressibility allows for increased stroke length and deeper drill depth into the drilling surface . . . . . . . . . . . . . . . . . . 26

3.4 Mass comparison of traditional metal bellows and comparable origami-based bellows. . . . . . . . . . . . . . . . . . . . . . 27

3.5 Kresling pattern. . . . . . . . . . . . . . . . . . . . . . 27

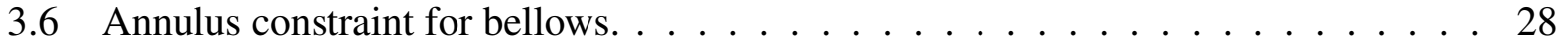

3.7 Final design concepts for origami-based bellows. . . . . . . . . . . . . . 30

3.8 Rotation of bellows prototype using origami design. . . . . . . . . . . . . 31

3.9 Creating and maintaining an adequate seal is a challenge for origami bellows design. 34

3.10 Various configurations for possible seam closure. . . . . . . . . . . . . . . 34

3.11 Different testing configurations for testing seam closure design. Blue regions represent bonded areas. . . . . . . . . . . . . . . . . . . . 36

3.12 Final bellows for ARM application. . . . . . . . . . . . . . . . . 38

3.13 Bellows mounted within aluminum slotted plate. . . . . . . . . . . . . . . . 39

$3.14 \operatorname{Tedlar}^{\circledR}$ samples bonded to aluminum using various epoxies. . . . . . . . . . . . 39

3.15 Load at failure in Tedlar ${ }^{\circledR}$ using different epoxies to bond to aluminum. Samples were tested at $-196^{\circ}$ C . . . . . . . . . . . . . . . . . 40

3.16 Tedlar $^{\circledR}$ samples tested to failure failed at corners where stress concentrations were greatest. . . . . . . . . . . . . . . . . . 41

3.17 Asymmetric compression after repeated cycling at $-80^{\circ} \mathrm{C} \ldots \ldots \ldots 42$

3.18 Prototype origami-based bellows mounted within Microspine tool. . . . . . . . . . 43 


\section{CHAPTER 1. INTRODUCTION}

\subsection{Motivation}

Operating mechanisms in outer space can provide many useful benefits in celestial and terrestrial spheres. Satellites provide many services to Earth-based operations and applications, space-based telescopes have deepened our understanding of the beginnings of the universe, and solar-system bound spacecraft investigate our neighboring planets. While space-based systems continue to provide benefits, they come with many challenges. Extreme temperatures, meteoroids, debris, and radiation can damage or congest sensitive instruments, greatly complicate spacecraft design. Spacecraft bound for terrestrial applications outside of Earth are prone to damaging gasses and ablation.

Sensitive instruments on spacecraft can consist of gears, pulleys, shafts, electronics, or other moving parts. If sensitive parts are exposed to the extreme conditions present in space, mission success is jeopardized. Designers have used various devices and techniques to protect these parts. One such device is a bellows.

Bellows are used to protect sensitive parts during operation while allowing axial motion to occur. They are used as a protective barrier on machineways, Jetways ${ }^{\circledR}$, automobile seats, cameras, mechanical seals, pressure gauges, and many other applications. While terrestrial applications have allowed for divergence in material and design selection in bellows manufacture, the harsh conditions of outer space have dissuaded investigation into alternative design approaches for space-bound bellows. Currently, space bellows are manufactured by welding individually-shaped diaphragms concentrically into a specified length. These bellows are almost exclusively created from metal to meet the environmental demands of space.

Space bellows require a large amount of design and investment. It can be challenging to design metal space bellows with sufficient compression ratios and low mass to make them useful on spacecraft. Current compression ratios of metal bellows often constrain spacecraft design, 
forcing structures to be extended along the axial direction of the bellows to accommodate for the compression capacities of the bellows. The bellows can be seen in many ways as a cylindrical compression spring that becomes more prone to buckling as it is compressed, increasing parasitic reaction forces and complicating analysis of force outputs within the spacecraft.

The ancient art of origami can be used to design mechanisms that will collapse into small volumes and expand to a relatively large volume. Origami has the potential to create low-mass mechanisms that are easily actuated and offer possibilities unattainable through traditional design methods. This thesis provides an alternative design method that circumvents the challenges of traditional space bellows by utilizing origami.

\subsection{Objective}

The objective of this work is to develop and demonstrate a method for designing origamibased bellows for harsh environments. This method will provide pattern selection options given design constraints for particular applications. Bellows design will be outlined for a given inner and outer diameter restriction and for stroke length requirements. Bellows will be designed, fabricated, and tested in a variety of harsh environments to verify their performance. The performance of origami-based bellows will be compared with metal counterparts to demonstrate that origamibased bellows provide improved performance, including reduced mass, reduced cost, reduced parasitic forces, and increased flexibility.

\subsection{Thesis Outline}

The approach taken in this thesis to describe the work accomplished is to highlight the need for improved bellows, establish a method for designing bellows, and use those methods to design and test bellows for varying applications.

Chapter 1 introduces the background and motivation behind this work while outlining its objectives.

Chapter 2 outlines methods for selecting an origami pattern for bellows selection and pro-

vides several options for consideration. Methods are provided to optimize patterns for spacial constraints. A bellows is designed for application on NASA's 2020 Mars Rover to protect actu- 
ating shafts for the rover's drill. Environmental testing verifies bellows performance in Martian conditions. This work has been presented and published in the ASME 2017 International Design Engineering Technical Conference.

Chapter 3 uses the methods developed in Chapter 2 to design a bellows for use on NASA's Asteroid Redirect Mission to contain debris during asteroid drilling and capture. Multiple design options are developed and considered for application. Methods of attaching bellows to spacecraft are matured. Techniques to close bellows seams are developed and tested at expected temperatures. Bellows are mounted to ARM drill prototypes and tested during drilling operations. This work has been submitted to the $68^{\text {th }}$ International Astronautical Congress.

Chapter 4 presents conclusions drawn from the accomplished work and discusses possible future research arising from the current results. 


\section{CHAPTER 2. ORIGAMI BELLOWS FOR MARTIAN ENVIRONMENT}

\subsection{Introduction}

The objective of this work was to develop a highly compressible origami bellows capable of withstanding the harsh environment of space application. This paper describes the results of evaluating origami bellows patterns and various materials in conditions comparable to those associated with a bellows in the drill of a Mars rover, but the results are applicable to a wide range of applications.

The origami bellows are compliant mechanisms because they use the deflection of flexible members to achieve their desired motion, force, or displacement. By relying on deflection for motion instead of rigid links and joints, compliant mechanisms can reduce complex, multi-part mechanisms into a single part. Potential advantages of compliant mechanisms over traditional mechanisms include fewer parts, ease of fabrication, reduced assembly, reduced cost, reduced weight, reduced friction, reduced wear, high precision, and no need for lubrication [1]. For these reasons, compliant mechanisms are highly applicable to harsh environments like outer space. In particular, advantages that are of interest in space applications are reduced weight, reduced friction, reduced wear, and no need for lubrication [2].

Origami-based mechanisms are a type of compliant mechanism inspired by the kinematics of origami models. In origami, creases in paper act as hinges to achieve motion from a single flat sheet. Origami is of particular interest in harsh and space environments for its stowability, deployability, and transportability.

Origami-based space mechanisms include antennas, solar arrays, and booms. The flasher fold pattern has inspired the design of antennas, solar arrays, sunshields, and solar sails that fold around a central hub during transport and deploy out radially for operation [3-5]. Other origamibased mechanisms rely on simple fold patterns like the $v$-fold to collapse long arrays or booms for solar sunshields [6]. Some mechanisms are not adapted directly from an origami fold pattern 


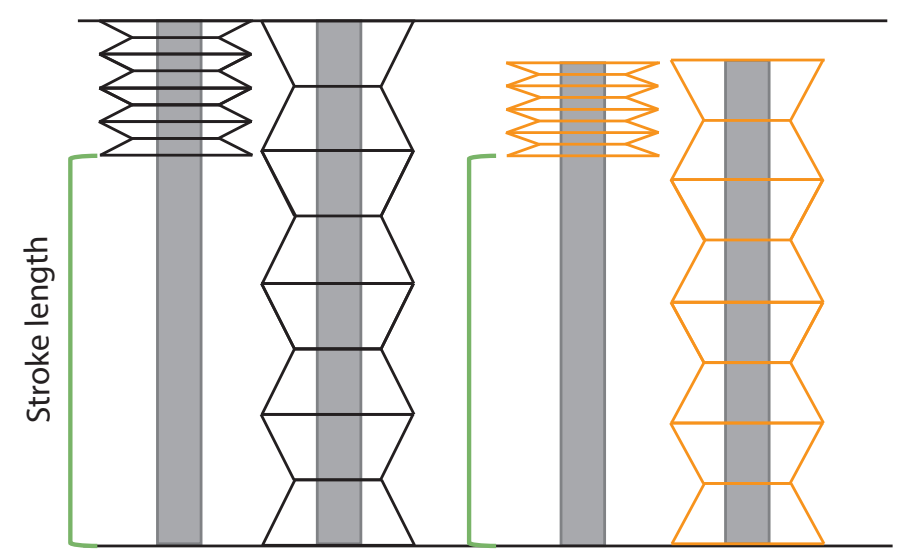

Figure 2.1: A highly compressible bellows reduces the length of the drill shaft, thus reducing weight and cost in space applications.

but still have elements of folding such as the James Webb Space telescope and Lang's eyeglass telescope [7]. Origami-based space mechanisms function as deployment mechanisms, protective shields, or structural supports that are compact for transport.

Additional space mechanisms possessing origami influence have been deployable cylinders with a wide range of applications such as inflatable booms and a sunshield for a deployable telescope using the Kresling and Tachi-Miura patterns [8,9]. This structure has a large range of potential applications both in space and on Earth including as a deployment mechanism, protective shield or barrier, or as structural support.

Origami based mechanisms could prove to be a viable solution to a need to develop a lightweight, highly-compressible deployable cylinder to protect the drill-guide shafts of an interplanetary rover from the harsh environment. This cylinder, referred to as a bellows, is a device with collapsible sides which allow it to deploy and contract while protecting a shaft within its walls. Currently, Mars rover drills use metal bellows to create a barrier between delicate shafts and Martian dust. These metal bellows have a compressibility ratio of approximately $66 \%$, meaning the compressed height is $34 \%$ of the deployed height. Designing a bellows with a higher compressibility ratio would decrease the necessary length of the drill shaft, as shown in Fig. 2.1. A highly compressible origami bellows that outperforms the metal bellows in compressibility will decrease the weight and cost of a rover for interplanetary and asteroid exploration. 


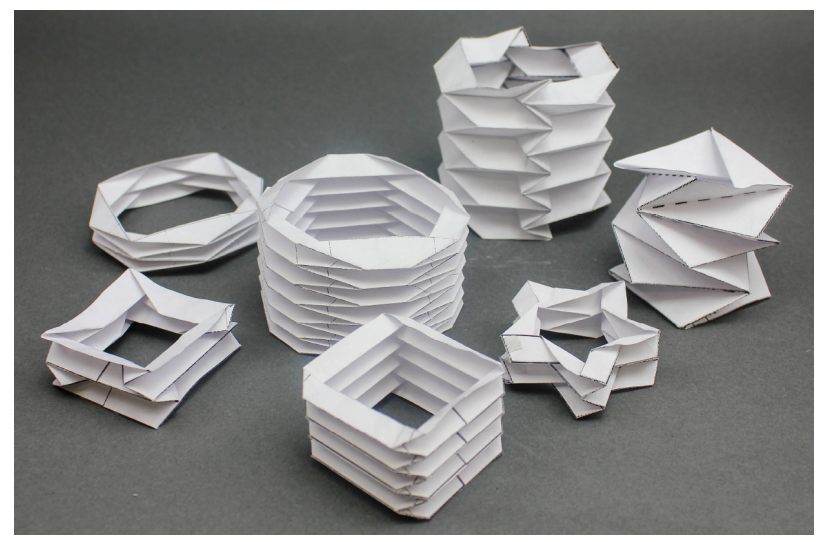

Figure 2.2: Possible origami models applicable to bellows.

For Martian applications, the environment introduces additional requirements on a bellows besides high compressibility. A bellows must be able to withstand 10,000 cycles at extreme temperatures, intense radiation exposure, and Martian sandstorms.

\subsection{Design and Selection of Highly Compressible Origami Bellows for Harsh Environments}

The origami bellows will be designed to be highly compressible and withstand a harsh environment. The main design variables are the origami fold pattern and the material.

\subsubsection{Possible Origami Fold Patterns}

There are several possible origami models that could function as a bellows, as shown in Fig. 2.2. Many patterns were analyzed, prototyped, and evaluated. After this initial study, three distinct models were evaluated in more detail: the Kresling and the Accordion shown in Fig 2.3, and the Tachi-Miura polyhedron shown in Fig. 2.4. Other models are either variations of these three or impractical to annulus constraints, such as the star-shaped bellows.

Wilson et al. designed an origami sunshield for a space telescope. Several fold patterns were investigated, including the Tachi-Miura and Kresling patterns. The Tachi-Miura polyhedron, shown in Fig. 2.4, is a rigid-foldable pattern, meaning that it experiences no strain in the panels. The advantage of the Tachi-Miura is the reduced stress on the bellows panels during cycling. The disadvantage of the Tachi-Miura polyhedron is the variable cross sectional area during deployment 


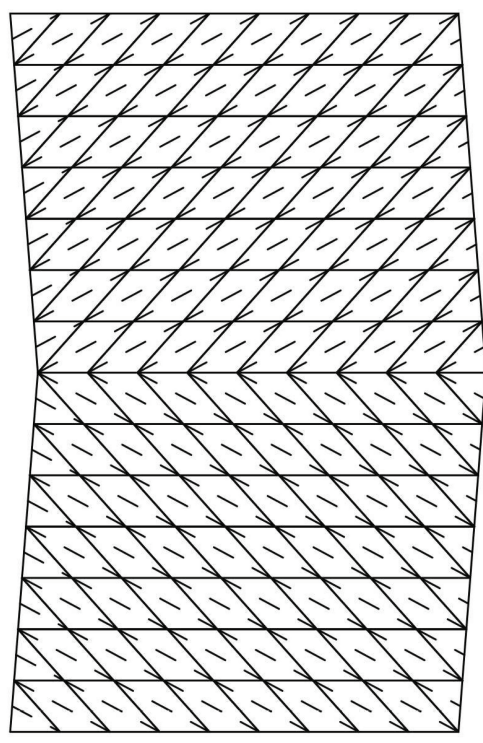

(a) Kresling fold pattern

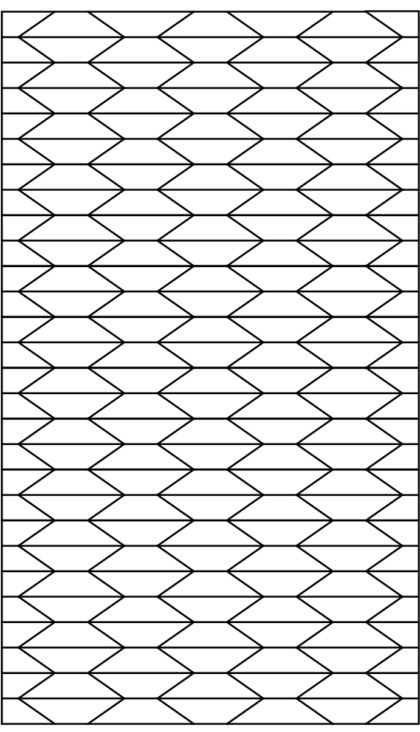

(b) Accordion fold pattern

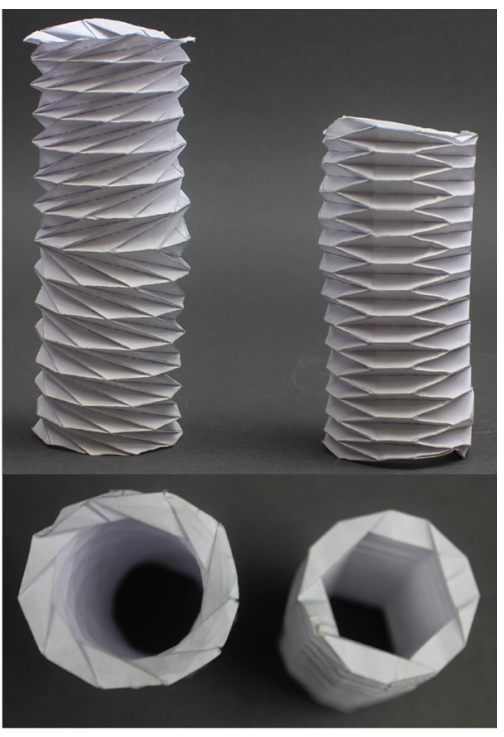

(c) Folded Kresling (left) and Accordion (right) bellows

Figure 2.3: (a) Kresling and (b) Accordion bellows patterns before and (c) after folding.

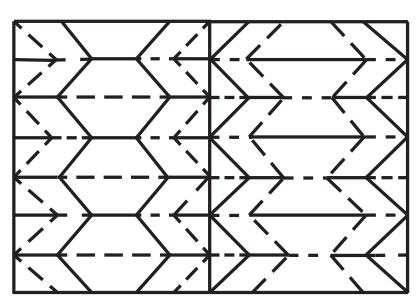

(a) Fold Pattern

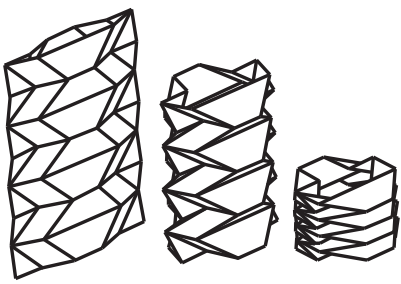

(b) Deployment Sequence

Figure 2.4: The Tachi-Miura Polyhedron.

as illustrated in Fig. 2.4 (b) [9]. Though the Tachi-Miura pattern can be modified to create a shape able to contain a shaft, doing so also increases strain during deployment. Additionally, to serve as an effective bellows for most applications, the ends must have a constant cross sectional area to simplify the interface between the device and where it will attach to the bellows. Clamping the ends of the Tachi-Miura pattern causes deformation in the panels during expansion. The changing cross sectional area also complicates the design to fit within the annulus constraints. For these reasons, the Tachi-Miura pattern was not selected for use in this application. 


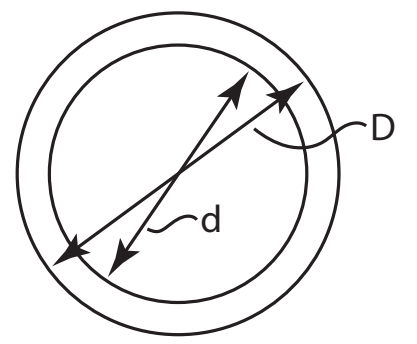

(a) Annulus formed by two concentric circles.

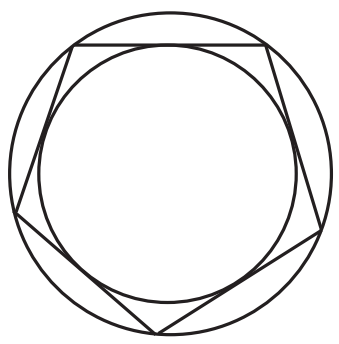

(b) A bellows pattern fit within an annulus.

Figure 2.5: Example of annulus constraints.

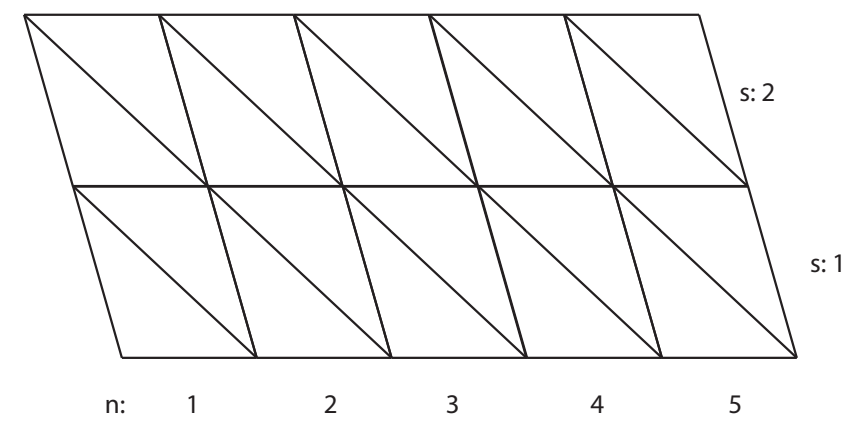

Figure 2.6: The tessellated Kresling pattern with $n=5$ and $s=2$.

\subsubsection{Origami Bellows Pattern Design and Selection}

The two remaining candidates for the bellows design are the Kresling and Accordion fold patterns, shown in Fig. 2.3. Neither of these fold patterns are rigid-foldable and will repeat stresses that could lead to fatigue in deflection cycling. Both fold patterns maintain a cross sectional area that remains within the annulus constraints.

The bellows' design is constrained by the outer diameter, $D$, the inner diameter, $d$, and the stroke length, $L$. Each bellows pattern is geometrically defined to fit the annulus of two concentric circles with the aforementioned diameters, as shown in Fig. 2.5. The remaining free variables used to define the pattern are $n$, the number of tessellated sides, and $s$, the number of stories or layers, as labeled in Fig. 2.6. The dependent variables are the side lengths $a, b$, and $c$, and the angle $\phi$, as shown in Fig. 2.7 for both the Kresling and Accordion fold patterns. 


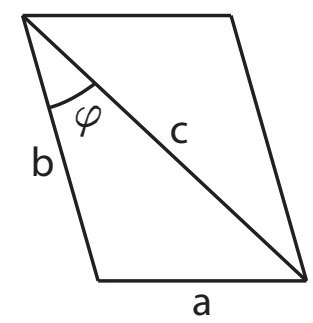

(a) Kresling

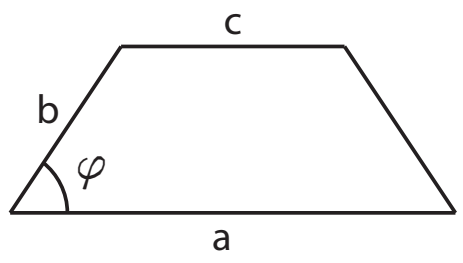

(b) Accordion

Figure 2.7: The Kresling and Accordion tessellation units.

The equations defining the Kresling tessellation unit are

$$
\begin{gathered}
a=D \sin \left(\frac{\pi}{n}\right) \\
b=D \sin \left(\arccos \left(\frac{d}{D}\right)-\frac{\pi}{n}\right) \\
c=D \sin \left(\arcsin \left(\frac{b}{D}\right)+\frac{\pi}{n}\right)
\end{gathered}
$$

and the equations defining the Accordion tessellation unit are

$$
\begin{gathered}
a=\sqrt{D^{2}-d^{2}} \\
b=D \sin \left(\arcsin \left(\frac{a}{D}\right)-\frac{\pi}{n}\right) \\
c=a-2 b \cos \left(\frac{\pi}{n}\right)
\end{gathered}
$$

To approximate the strain that the Kresling pattern undergoes when actuated, Jianguo et al. [10] developed the following equations to represent the strain, $\varepsilon$, in the valley fold side, $c$.

$$
\begin{gathered}
c=\sqrt{\left[D \sin \left(\frac{\pi}{n}+\arcsin \frac{b \cos \delta}{D}\right)\right]^{2}+(b \sin \delta)^{2}} \\
\varepsilon=\frac{c-c_{0}}{c_{0}}
\end{gathered}
$$


where $\delta$ is the deployment angle as shown in Fig. 2.8 and $c_{0}$ is the length of $c$ when $\delta=0$. The dimensionless strain energy, $w$, is proportional to $\frac{1}{2} \varepsilon^{2}$. However, it is assumed that $a$ and $b$ are constant and that all strain is modeled in terms of $c$ only [10].

The value of $n$ has a large influence on the design. For the Accordion tessellation unit, $n$ must be a even and $n \geq 4$. This fold pattern depends on having an equal number of sides. For the Kresling tessellation unit, $n$ must be greater than or equal to three. These equations define the shape of each tessellation unit and the number of sides in each layer.

For the Kresling pattern, there is a relationship between $n$ and the strain in the bellows. As $n$ increases, the amount of strain decreases but with diminishing return. When $n>9$, the influence of $n$ on the axial strain is slight [11]. Also, as $n$ increases, the number of folds increases and the fold lengths become extremely small. The value of $n=9$ is chosen for bellows design as it experiences significantly less strain than lower $n$ values while still providing feasible manufacture.

Though the number of sides $n$ is also related to strain in the Accordion pattern, a different side, $b$, as shown in Fig. 2.7 (b), is used for an analysis of the Accordion's strain because it experiences the maximum strain during deployment. As both patterns reach full deployment and are over-strained, vertices can buckle causing additional deformation. This can cause cyclical stresses at the vertices of the bellows, possibly leading to fatigue failure.

To prevent the bellows from buckling at a vertex, the bellows needs to have an adequate number of stories to protect the full stroke length of the drill shaft. It is desirable to use a minimal number of stories to reduce mass and compressed height. In contrast, fewer stories requires further deployment of each individual story. To reach the full stroke length, the number of stories can

Table 2.1: Comparison of Metal bellows, Accordion origami bellows, and Kresling origami bellows.

\begin{tabular}{|c|c|c|c|}
\hline & Metal Bellows & Accordion Bellows & Kresling Bellows \\
\hline \hline Compressibility (\%) & 66 & 94.0 & 95.5 \\
\hline Fabrication Folds & N/A & 522 & 59 \\
\hline Number of vertices & N/A & 261 & 150 \\
\hline
\end{tabular}

* Green cells indicate best performance for all options in each category 


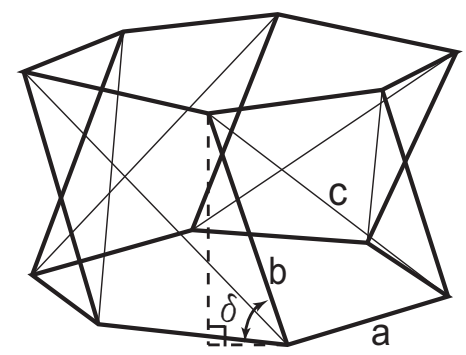

Figure 2.8: Single story Kresling showing the deployment angle, $\delta$.

be increased until the deployed length minus the compacted length is greater than or equal to the stroke length $\left(L_{d}-L_{c} \geq L\right)$.

Because the deployed length is dependent on the strain in the creases, it is necessary to keep the deployment angle $\delta$, shown in Fig. 2.8, within a specified value. Multiple prototyped bellows were deployed until buckling occured, showing that $\delta_{\max } \leq 35^{\circ}$ provides an cap value for $\delta$ that maximizes deployment while preventing buckling. Over-straining the system decreases the lifetime of the bellows. Since the height of a single story, $h$, is

$$
h=b \sin \delta
$$

the deployed height for a single story is then

$$
h_{\text {deployed }}=b \sin \delta_{\text {max }}
$$

and the total deployment of the bellows is

$$
H=s h_{\text {deployed }}
$$


This analysis of the Kresling and Accordion fold patterns leads to origami fold pattern designs that meet the bellows' requirements for the rover drill. A comparison of the Kresling and Accordion fold patterns designed to fit the annulus constraint are shown in Fig. 2.3.

The key factors in choosing a bellows are compressibility, manufacturability, and chance of failure. Table 2.1 shows a comparison of the Kresling, Accordion, and Metal bellows in relation to these key factors which are also discussed below.

Compressibility is the ratio of change in height to deployed height as given by

$$
\text { compressibility }=\frac{h_{\text {deployed }}-h_{\text {compressed }}}{h_{\text {deployed }}}
$$

Both origami designs with compressibilities over $90 \%$ outperform current metal bellows which have $66 \%$ compressibility.

Manufacturability of an origami bellows is highly dependent upon the number of fabrication folds required to make the bellows. Patterns with long, continuous folds are more manufacturable than a bellows with many short folds. The differences in fabrication fold length are compared between the Kresling and Accordion patterns in Fig. 2.3. As shown in Table 2.1, the Kresling pattern's 59 fabrication folds are far less than the 522 folds of the Accordion.

Decreasing the likelihood of failure is another important aspect of the design. By minimizing the number of vertices, the bellows is less likely to fail at any single vertex. The Kresling pattern yields 150 vertices in comparison to the Accordion pattern's 261.

Both the Kresling and Accordion outperform the Metal bellows in compressibility. The Kresling outperforms the Accordion in compressibility, fabrication complexity, and number of vertices, so it was chosen as the fold pattern for the origami bellows.

\subsubsection{Materials}

Due to the harsh environment of space, the materials to be used for the bellows is of special concern. For example, the Martian environment presents extreme temperature fluctuations, high UV radiation, and occasional dust storms. Other factors to consider in the material selection in-

clude folding endurance, the ability of a material to hold a paper-like crease, and the simplicity 


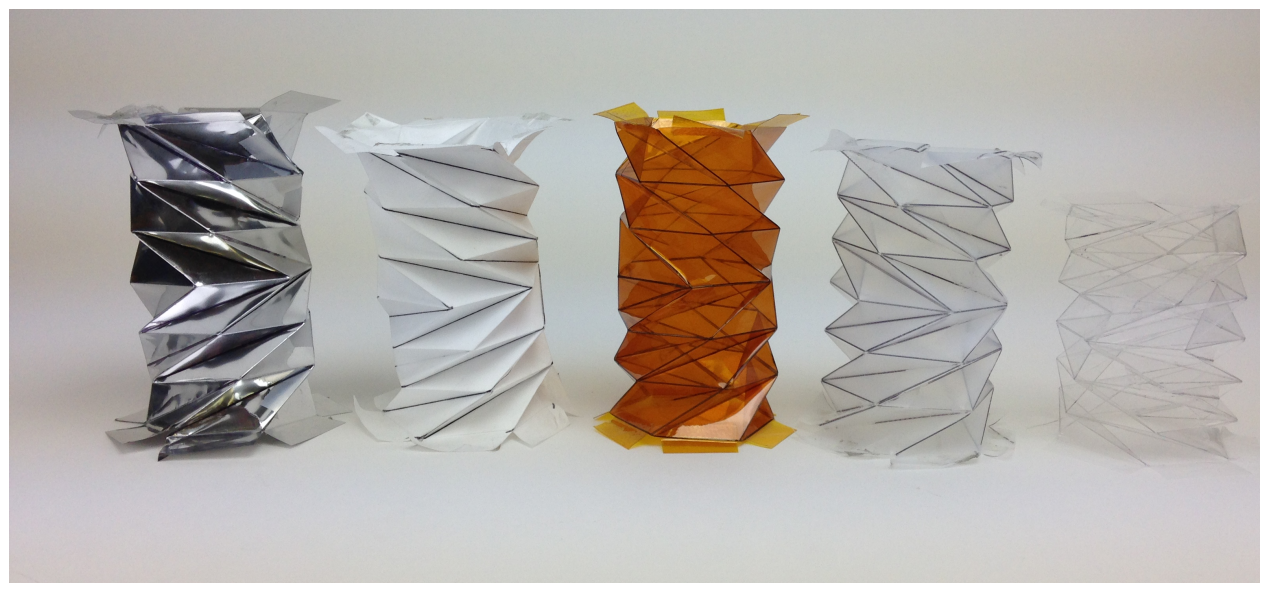

Figure 2.9: Materials tested in the Kresling fold pattern from left to right: Mylar ${ }^{\circledR}$, Tyvek $^{\circledR}$, Kapton $^{\circledR}$, UHMWPE, and ETFE.

of fabrication that could be used with each material. Materials were chosen from known spacegrade materials and their capacity for creasing. Space-rated materials that are readily available and possess high strength characteristics include Kapton ${ }^{\circledR}$, ETFE, and Mylar ${ }^{\circledR}$. Other materials that perform well in origami applications are Tyvek ${ }^{\circledR}$ and UHMWPE. These five materials were chosen to test for comparison of performance in origami space bellows. Figure 2.9 shows the five chosen materials folded in the Kresling fold pattern with a material thicknesses of $0.05 \mathrm{~mm}(0.002$ inch).

\subsubsection{Fabrication}

To create test articles, simplified bellows, shown in Fig. 2.9, were fabricated by hand using folding techniques. The folding is initiated by embossing the fold pattern into the material. The embossing is done using a ball point pen and pressing firmly while tracing the folding lines printed on a separate sheet of paper. Once all of the creases are initiated, they are folded individually to form sharp creases.

After the creases are established, the sheet is formed into a cylinder using an adhesive or by welding the plastic film together. The adhesive needs to be able to withstand the same extreme environmental conditions as the material. Two adhesives that meet the high and low temperature requirements for Mars-like environments $\left(-70^{\circ} \mathrm{C}\right.$ to $\left.20^{\circ} \mathrm{C}\right)$ are Kapton ${ }^{\circledR}$ tape and $3 \mathrm{M}$ Adhesive 


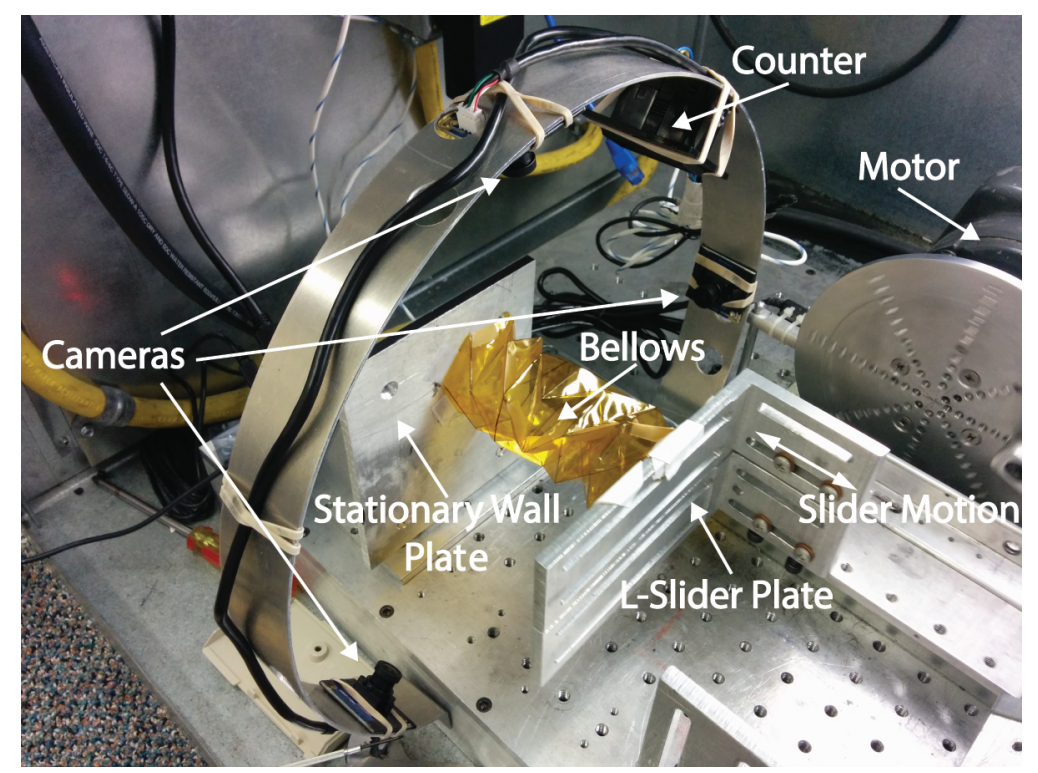

Figure 2.10: Fatigue testing apparatus.

Transfer tape. The Kapton ${ }^{\circledR}$ tape is Kapton ${ }^{\circledR}$ based using silicone adhesive. The $3 \mathrm{M}$ Adhesive Transfer tape is an acrylic adhesive and requires overlapping sections on the bellows. The adhesive will undergo the same testing as bellows materials.

\subsection{Testing}

The highly compressible origami bellows underwent a series of testing to evaluate its suitability for harsh environments. The bellows needs to endure deflection cycling, thermal cycling, ablation, and radiation exposure. Each material listed in Fig. 2.9, folded in the Kresling fold pattern, was subjected to these tests to evaluate its environmental limitations.

The testing focused on ensuring the bellows can endure the Martian environment but can be applied to other harsh environment situations. For a Mars rover application, the origami bellows should withstand a minimum of 10,000 cycles, thermal cycling between $-70^{\circ} \mathrm{C}$ and $20^{\circ} \mathrm{C}$, resist ablation from sand storms, and not break down from intense UV Radiation.

A summary of the test results is listed in Table 2.2. 


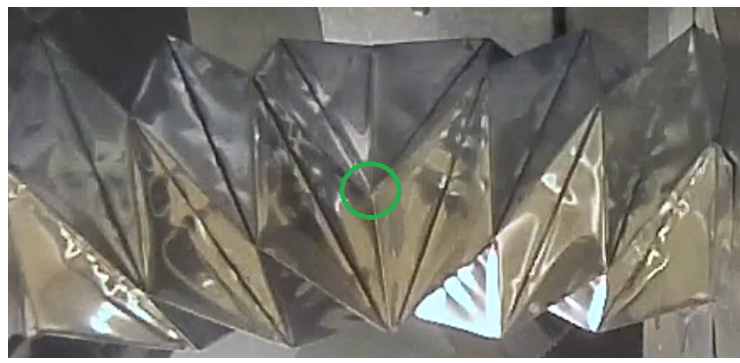

(a) Before failure

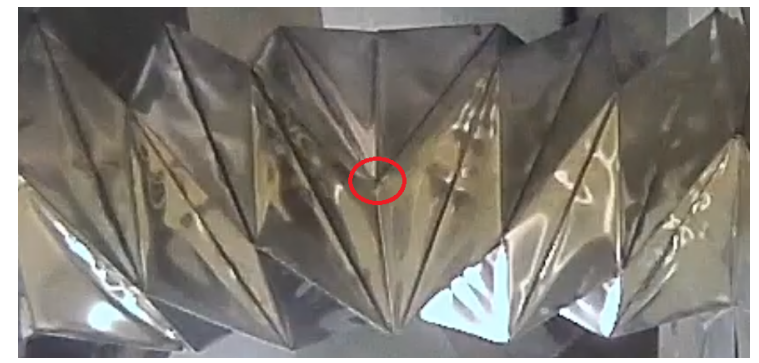

(b) After failure with a hole in the central vertex

Figure 2.11: A bellows in the fatigue tester.

\subsubsection{Fatigue}

The bellows were cycled over their stroke length in a custom-designed fatigue tester as seen in Fig. 2.10. The fatigue tester consists of a crank-slider mechanism attached to a motor. The bellows are attached to the slider portion of the mechanism and a base plate using an adhesive. Three cameras were placed around the bellows that periodically take pictures of the bellows during cycling to document the time of failure. A simplified Kresling pattern consisting of six sides and six stories was fabricated out of each material and placed in the fatigue tester until failure or 100,000 cycles, whichever occurred first.

The design of the Kresling fold pattern results in stress concentrations that can contribute to fatigue failure. The point of initial failure for the majority of cases is observed at the midsection vertex opposite of the tape seam as shown in Fig. 2.11. A possible explanation of this result is the change in fold direction that occurs at this vertex. The results of the testing are shown in Table 2.2. The Mylar ${ }^{\circledR}$ failed first at the required 10,000 cycles while the rest of the materials exceeded the 10,000 cycle requirement.

\subsubsection{Thermal Cycling}

Mars has temperature ranges from $-125^{\circ} \mathrm{C}$ to $20^{\circ} \mathrm{C}$ and the origami bellows is required to withstand a temperature range of $-70^{\circ} \mathrm{C}$ to $20^{\circ} \mathrm{C}$ at expected latitudes. The temperature will cycle between these two temperature extremes on a daily basis which can cause thermal fatigue failure. Both the material and adhesive need to endure the thermal cycling. 


\section{Material}

To test the thermal cycle fatigue life, the origami bellows were thermally cycled between dry ice $\left(-79^{\circ} \mathrm{C}\right)$ and ambient temperatures $\left(20^{\circ} \mathrm{C}\right)$ for approximately 60 cycles. The temperature of dry ice is a close estimate to expected low temperatures on Mars. After thermal cycling, the bellows were subjected to deflection cycling. Even after thermal cycling, all the materials were able to endure over 10,000 cycles. All the materials were allowed to run to 30,000 cycles with no signs of failure except for ETFE, which developed a hole on the midsection vertex after $\sim 25,000$ cycles.

The materials endured the thermal cycling without failure when tested with both Kapton ${ }^{\circledR}$ tape and 3M Adhesive Transfer tape. The Kapton ${ }^{\circledR}$ tape is rated to a temperature range of $-73^{\circ} \mathrm{C}$ to $260^{\circ} \mathrm{C}$ while the $3 \mathrm{M}$ Adhesive Transfer Tape is rated from $-40^{\circ} \mathrm{C}$ to $121^{\circ} \mathrm{C}$.

Any combination of adhesive and material for the origami bellows should withstand the thermal cycling experienced on a Mars rover contingent upon adhesives remaining within that given temperature range. Though the Transfer Tape showed promise by withstanding thermal cycling and fatigue testing, its temperature limitations make it a secondary choice to Kapton ${ }^{\circledR}$. It also requires an overlap of materials to seal the bellows. This overlap interferes with compressibility. Though both adhesives provide an adequate bond, Kapton ${ }^{\circledR}$ tape was chosen for further testing on the origami bellows.

\section{Welding}

As an alternative to eliminate the thermal limitations of using an adhesive, the origami bellows can be sealed using a weld. Advantages of welding include increased efficiency and accuracy of the manufacturing process and greater capacity for high volume applications. However, welding can increase stiffness of the material at the weld location and some materials, such as Kapton ${ }^{\circledR}$, are not easily welded.

For low volume applications, especially those where compressibility is the driving design factor, adhesives become a more practical and efficient choice. Thus, adhesives were used for further testing. 


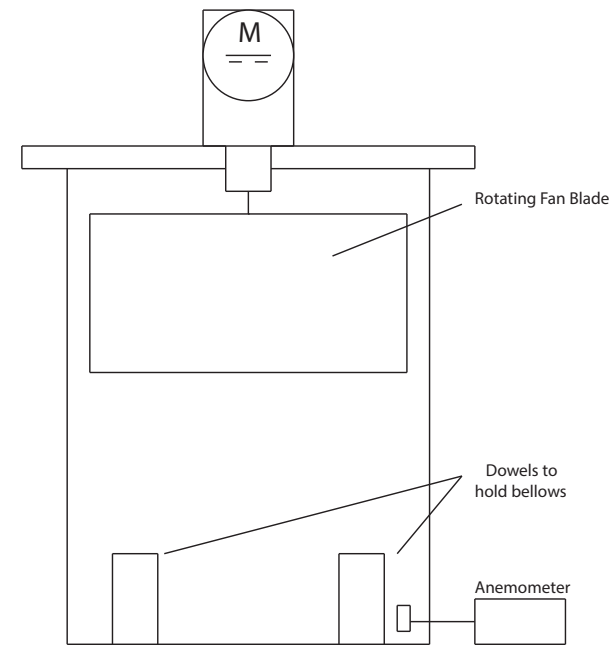

(a) Diagram of testing apparatus.

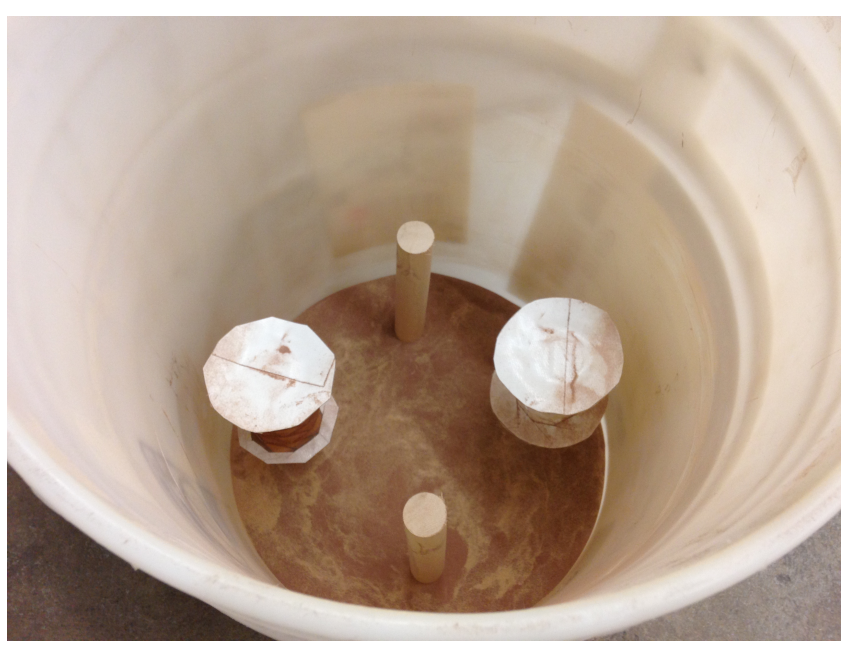

(b) Vertical view of apparatus showing replicated Martian sand.

Figure 2.12: Sandstorm simulation apparatus.

\subsubsection{Ablation}

A bellows provides protection from sand jamming the sliding mechanisms within the drill shaft. Martian sandstorms occur frequently and though wind speed maintains an average of 8.9 $\mathrm{m} / \mathrm{s}$ (20 mph), recorded speeds have been measured up to $33 \mathrm{~m} / \mathrm{s}(74 \mathrm{mph}$ ) [12]. These winds pick up dust that will scrape the surface of exposed material. Fortunately, Martian atmospheric pressure is approximately 168 times lower than that on Earth of $600 \mathrm{~Pa}$ (0.087 psi) [13], thus restricting airborne particles in size. [14]

The origami bellows were subjected to a mock sandstorm test at standard temperature and pressure using particles filtered to appropriate Martian dust size of 180 microns. Tests were performed at $15.6 \mathrm{~m} / \mathrm{s}(35 \mathrm{mph})$ for 24 hours in the apparatus shown in Fig. 2.12. The samples' masses were measured before and after the sandstorm testing. The percentage mass change was a slight increase of negligible size in all samples due to particle adhesion except for Tyvek ${ }^{\circledR}$. Tyvek ${ }^{\circledR}$ has a woven fiber structure that significantly increases the amount of dust particles it gains. Also, $\mathrm{Mylar}^{\circledR}$ had its reflective coating ablated off in testing. Mass loss was evident but difficult to measure due to adhered dust. 


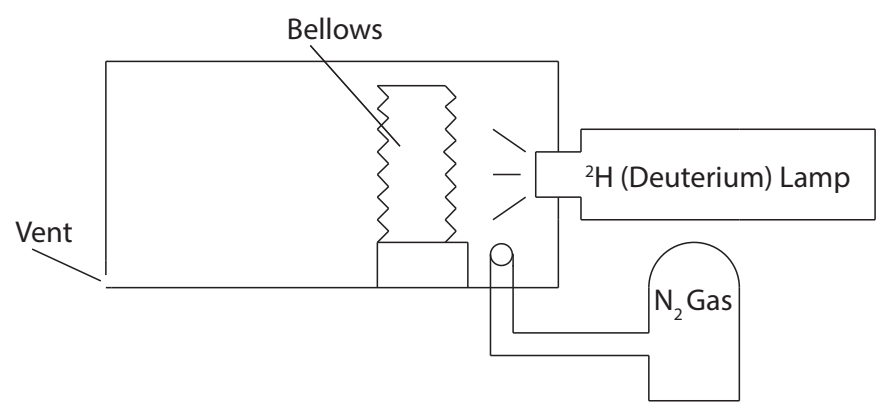

(a) Diagram of testing apparatus

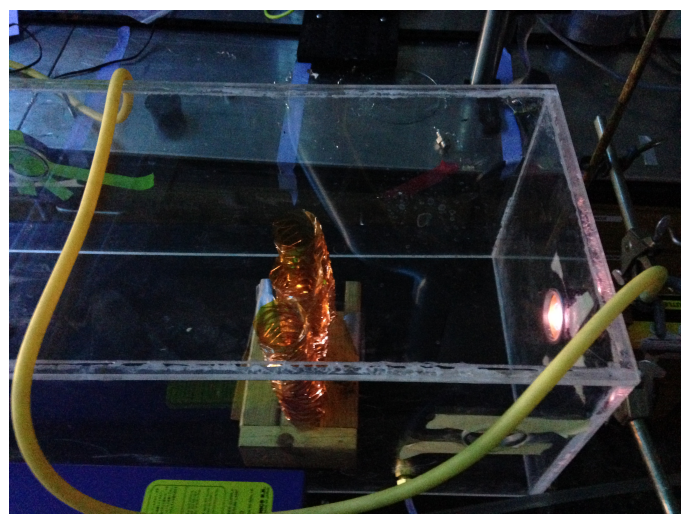

(b) Bellows prototypes during UV testing

Figure 2.13: UV simulation apparatus.

\subsubsection{Radiation}

The Martian environment experiences a large flux of radiation due to lack of atmospheric protection. Earth's magnetosphere protects its surface from high energy ultraviolet (UV) radiation known as UV-C. UV radiation consists of electromagnetic waves ranging from 100-400 nm wavelengths. UV-C is the most energetic of these waves, consituting the 100-290 nm portion of the UV range. Most materials absorb UV-C at the atomic level, causing binding electrons to become excited and break bonds between atoms. Over time this causes a material to degrade, discolor, and crack. Current readings from the Mars Science Laboratory (Curiosity) rover indicate average $\mathrm{UV}-\mathrm{C}$ readings peaking at $2 \mathrm{~W} / \mathrm{m}^{2}$ at midday and a combination of all $\mathrm{UV}$ peaking at $20 \mathrm{~W} / \mathrm{m}^{2}$ at midday [15]. This equates to roughly $11 \mathrm{wH} / \mathrm{m}^{2}$ of UV-C and $100 \mathrm{wH} / \mathrm{m}^{2}$ of total UV during an average Martian day.

NASA collected information regarding effects of particle radiation to various common space polymer materials. They report that Kapton ${ }^{\circledR}$ can withstand $>100$ Mrad, Mylar ${ }^{\circledR}$ can withstand $>1$ Mrad, and UHMWPE can withstand $>10$ Mrad before moderate degradation effects the material [16]. UHMWPE has been used for radiation shielding in spacecraft against galatic cosmic rays and solar energetic particles but breaks down due to proton irradiation [17]. Kapton ${ }^{\circledR}$ and Mylar ${ }^{\circledR}$ are common space materials due to their resistance to degradation in high UV environments. ETFE is mostly UV transparent for the frequencies experienced on Earth and has been used as an electrical-cable-jacket in spacecraft. When exposed to space environments it discolors 
and begins to crack making it unsuitable for longterm missions [18]. Tyvek ${ }^{\circledR}$ is not a space-grade material and breaks down from UV exposure on Earth's surface. Coatings can be added to Tyvek ${ }^{\circledR}$ to make it more resistant to UV.

The literature suggests that Kapton ${ }^{\circledR}$ is most suited for radiation exposure while ETFE and Tyvek $^{\circledR}$ will degrade in extreme radiation exposure.

Preliminary radiation testing of the origami bellows covering the expected UV spectrum was simulated using a $100 \mathrm{~W}$ deuterium lamp as seen in Fig. 2.13. The deuterium lamp emits a spectrum of UV ranging from 200-400 nm radiation. Testing included higher ratios of UV-C-to$\mathrm{UV}-\mathrm{A} / \mathrm{UV}-\mathrm{B}$ than the expected conditions. UV-C is of highest concern and is the most destructive so high exposure to UV-C was preferred.

Bellows made from Kapton ${ }^{\circledR}$, UHMWPE, UHMWPE with carbon black, and PFA were exposed to $100 \mathrm{~W}$ of UV for 36 hours which equates to $\sim 2$ years of UV exposure on Mars.

Since all materials did well under the two year radiation testing conditions and because of literature recommendations of Kapton ${ }^{\circledR}$ use in radiation over UHMWPE, Kapton ${ }^{\circledR}$ was chosen for the next phase of testing.

Table 2.2: Screening study of the origami bellows test results for harsh environments. The adhesive refers to both the Kapton ${ }^{\circledR}$ tape and 3M Transfer Tape. Note that this data represents single-sample screening for material properties.

\begin{tabular}{|c|c|c|c|c|c|}
\hline & Kapton $^{\circledR}$ & Mylar $^{\circledR}$ & ETFE & Tyvek $^{\circledR}$ & UHMWPE \\
\hline \hline $\begin{array}{c}\text { Deflection cycling } \\
\text { (cycles) }\end{array}$ & $100,000^{*}$ & 10,000 & 15,000 & $100,000^{*}$ & $100,000^{*}$ \\
\hline $\begin{array}{c}\text { Fatigue after thermal } \\
\text { cycling (cycles) }\end{array}$ & $30,000^{*}$ & $30,000^{*}$ & 25,000 & $30,000^{*}$ & $30,000^{*}$ \\
\hline Adhesive (dry ice) & pass & pass & pass & pass & pass \\
\hline $\begin{array}{c}\text { Ablation mass change } \\
(24 \text { hrs) }\end{array}$ & negligible & negligible & negligible & $\begin{array}{c}\text { measurable } \\
\text { increase }\end{array}$ & negligible \\
\hline UV Radiation (36 hrs) & pass & not tested & not tested & not tested & pass \\
\hline
\end{tabular}

$*$ Deflection cycling was stopped after the concept had been demonstrated.

$* *$ Green cells indicate best performance for all options in each category. Red cells indicate poor performance. 


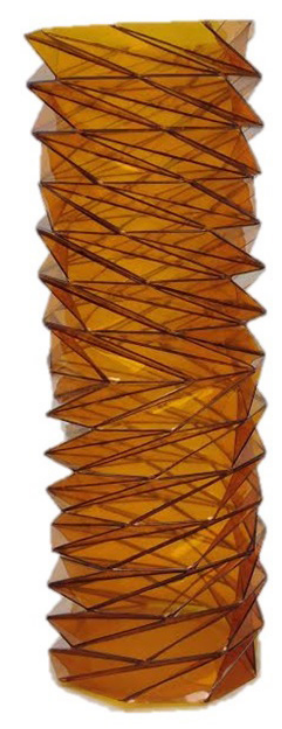

(a) Deployed.

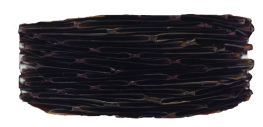

(b) Compressed.

Figure 2.14: Full-size Kapton ${ }^{\circledR}$ prototype.

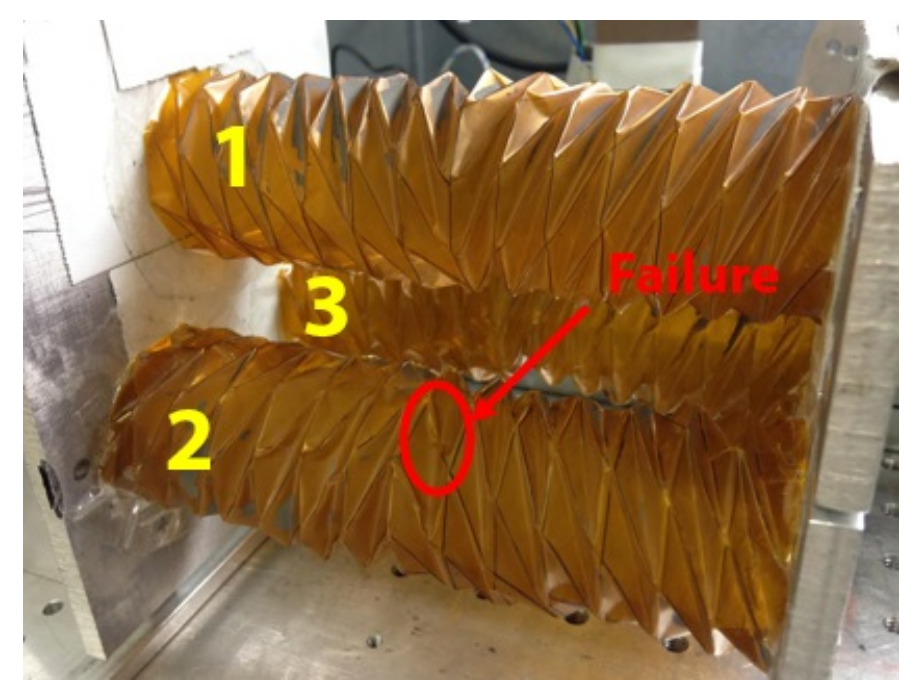

Figure 2.15: Three full-size Kapton ${ }^{\circledR}$ prototypes under fatigue testing. Failure occuring on Bellows 2 at predicted fold.

\subsubsection{Full Prototype Testing}

Origami bellows using a Kresling pattern with $n=9, s=14$, and made of Kapton ${ }^{\circledR}$ were fabricated for testing through all four different environmental tests (Fig. 2.14). Three origami bellows were constructed from 2 mil Kapton ${ }^{\circledR}$ film and were adhered along the seam with 3/4 in. 
width and 1 mil thick Kapton ${ }^{\circledR}$ tape. These bellows were tested through 36 hours of UV exposure, 24 hours of sandstorm simulation, 62 thermal cycles, and at least 10,000 cycles of fatigue testing. The results of the testing are listed in Table 2.3.

Each of the bellows surpassed each testing condition. No damage was evident from UV exposure. A slight gain in mass occurred on each bellows due to particle adhesion but did not affect the functionality of the bellows. No change was evident after thermal cycling. Each of the bellows did not fail before the designated 10,000 cycles. Upon construction and before testing, it was observed that Bellows 2 had a fold with poor fold quality that would buckle each time the bellows was compressed. Shown in Fig. 2.15, it was at this point on bellows 2 that failure occurred after 15,000 cycles.

\subsection{Conclusion}

For a highly compressible origami bellows on a space mechanism, Kapton ${ }^{\circledR}$ with a Kapton ${ }^{\circledR}$ tape adhesive is well suited for the application and desired lifetime. Failure locations can be predicted on the bellows by inspection of each of the folds. Fold quality affects the life of the bellows but even hand-folded bellows demonstrated fatigue life exceeds expectations. Kapton ${ }^{\circledR}$ was chosen for this application since it has been demonstrated in space environments and is known to endure in high UV environments. The Kapton ${ }^{\circledR}$ bellows demonstrated good fatigue life even after being subjected to thermal cycling, UV exposure, and windstorm testing. The Transfer tape does

Table 2.3: Results of full-size Kapton ${ }^{\circledR}$ prototype testing.

\begin{tabular}{|c|c|c|c|}
\hline & Bellows 1 & Bellows 2 & Bellows 3 \\
\hline \hline $\begin{array}{c}\text { UV Radiation Damage } \\
\text { (36 hours) }\end{array}$ & None Observed & None Observed & None Observed \\
\hline $\begin{array}{c}\text { Sandstorm Mass } \\
\text { Change and Damage } \\
(24 \text { hours })\end{array}$ & Slight mass gain & Slight mass gain & Slight mass gain \\
\hline $\begin{array}{c}\text { Thermal Cycling (62 } \\
\text { cycles) }\end{array}$ & Pass & Pass & Pass \\
\hline Deflection Cycling & $100,000^{*}$ & 15,000 & $100,000^{*}$ \\
\hline
\end{tabular}

* Deflection cycling was stopped at 100,000 cycles without failure. 
have thermal limitations but works in the set temperature range a Mars rover will experience. Sand storms on the surface of Mars will cause sand to adhere to the material but will not cause punctures or holes at the vertices resulting in failure.

The research results can be used to develop highly compressible origami bellows subjected to harsh environments. The origami bellows show fatigue life exceeding 100,000 cycles for some materials and resilience to potential harsh environmental conditions including thermal cycling, abrasion, and high radiation. The Kresling fold pattern can be designed to fit within a given inner and outer diameter and stroke length depending on the design requirements. The origami bellows may be an advantageous replacement for current metal bellows due to its high compressibility and low mass. Martian rover drill shafts are only one possible application of an origami bellows in space or interplanetary missions.

The result for the highly compressible origami bellows for harsh environments can be used to design a bellows to other design requirements. Origami bellows show promise in applications such as deployment mechanisms, protective shields or barriers, or structural supports. 


\section{CHAPTER 3. ORIGAMI BELLOWS FOR MICROGRAVITY DRILLING}

\subsection{Introduction}

The objective of this work was to develop methods and an apparatus for containing drilling debris in microgravity, specifically for use in outer space and its associated harsh environment. This paper describes the results of designing and evaluating origami-based bellows as a solution for dust containment during microgravity drilling.

The harsh environments of outer space create difficulties when operating space-based mechanisms. Outgassing of lubricants, high mass, large volume, manufacturing complexity, and joint binding increase the risk of spacecraft failure [2]. Many of these challenges can be overcome by employing compliant mechanisms. Utilizing compliance in mechanism design can both reduce cost and increase performance by reducing part-count, wear, mass, and maintenance while increasing precision and reliability [1].

Origami-based mechanisms are an example of compliant mechanisms uniquely suited for space applications. While they maintain many of the benefits of compliant design, they are capable of large compression-to-deployment ratios. Origami-based mechanisms require no lubrication and can be designed using already tested and flight approved materials. The benefits of origami-based space design have been demonstrated as viable and effective in NASA's star shade [4], deployable solar panels [3], parabolic antennas [5], inflatable structures [8, 19], the James Webb telescope, Lang's Eyeglass [7], sunshields for space telescopes [9], and highly compressible bellows [20].

The potential benefits of an origami-based solution created an opportunity for application on NASA's Asteroid Redirect Mission (ARM). It would collect a multi-ton boulder and use the boulder to perform an Enhanced Gravity Tractor asteroid deflection demonstration. The boulder would then be transported to a stable orbit around the Moon where astronauts will be able to investigate the boulder and return findings to Earth [21]. 


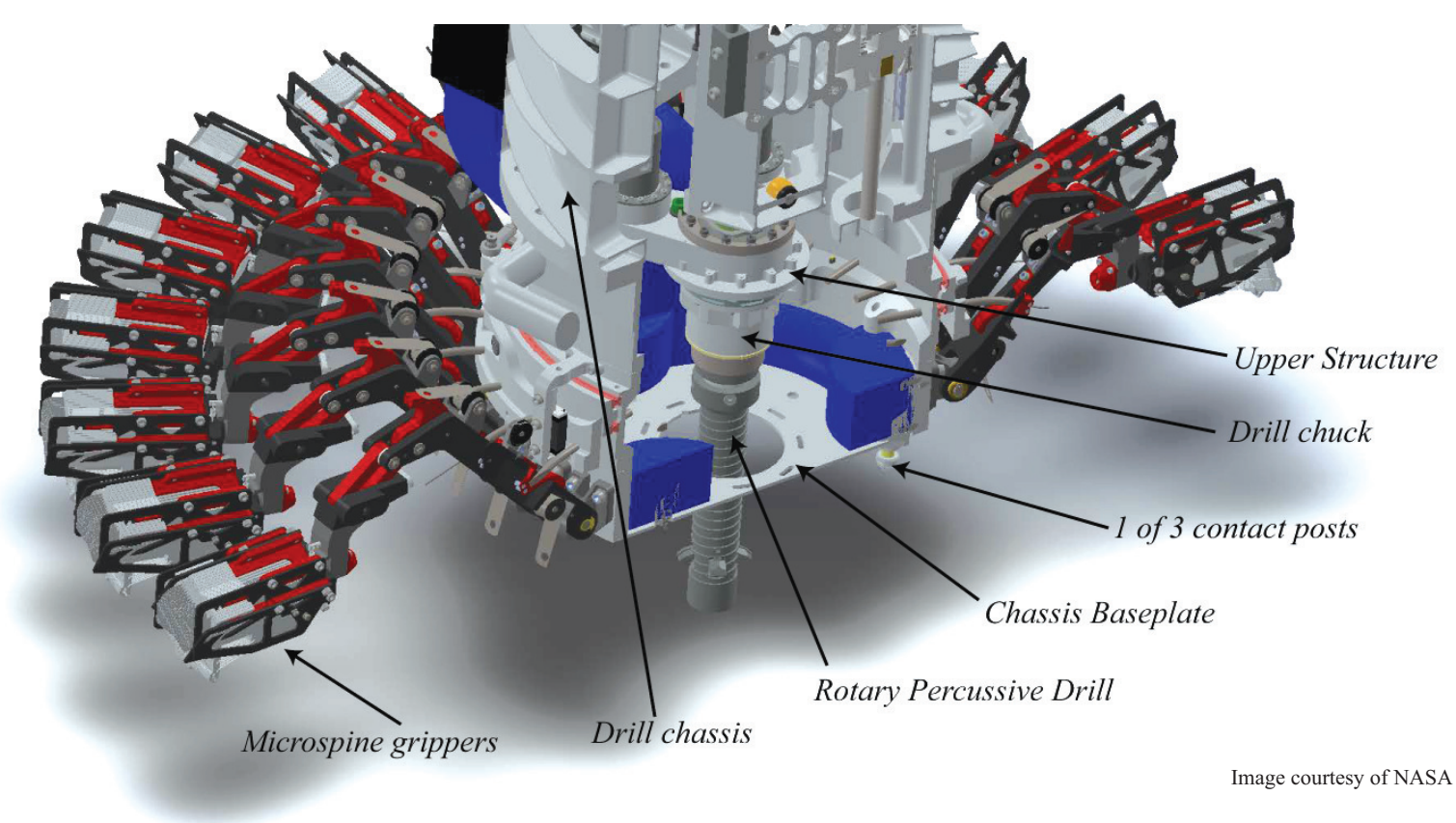

Figure 3.1: Microspine tool for the Asteroid Redirect Mission (ARM)

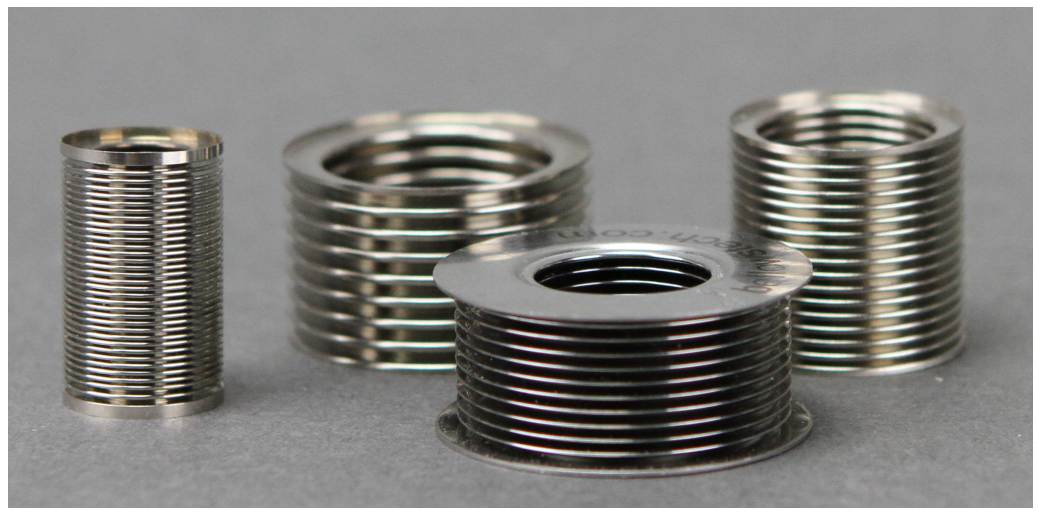

(a) Traditional metal bellows.

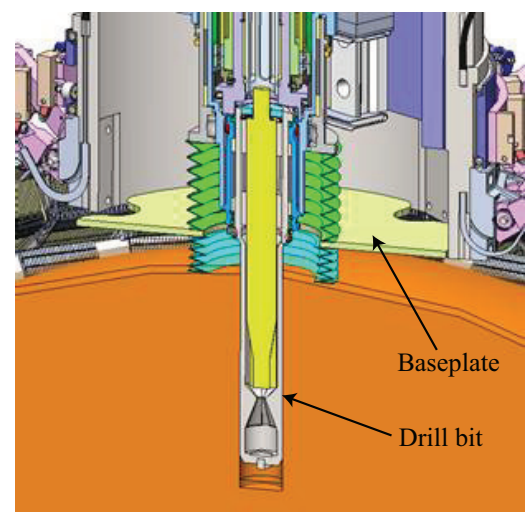

(b) The bellows, illustrated in green, will encase the drill bit within the chassis.

Figure 3.2: Traditional metal bellows and the need to protect the inner ARM drill mechanisms from debris.

During the surface phase of the ARM, NASA plans to land the spacecraft on the asteroid, straddling a 1 to 4 meter boulder. Two robotic arms with Microspine Tools (Figure 3.1) would then secure the boulder before extraction. This sequence begins by aligning a tool to the local boulder 
surface normal using three contact posts. The microspine gripper then stabilizes the arm, and is used to react the forces and torques of drilling into the boulder [22]. Once a sufficient depth has been reached, an anchoring feature in the drill bit is deployed that cuts a groove in the bottom of the borehole. This provides a geometric anchor point with the boulder [23]. The drilling and anchoring operations will create significant debris that, if left unconfined, could drift in the microgravity environment and contaminate sensitive parts within the tool and degrade or potentially inhibit its function.

Shown in Figure 3.2(a) are axially-compressing metal bellows commonly used to protect sensitive parts of machinery. Bellows are found in a diverse range of terrestrial applications, including machine way covers, cameras, Jetways ${ }^{\mathrm{TM}}$, and automobile seats. In space, bellows are frequently used to protect sensitive instruments and moving parts from dust and debris. Spacecraft have traditionally relied upon metal bellows for protection. Origami-based bellows offer opportunities to reduce mass, improve compression to extension ratios, and lower reaction forces during compression. They also have the flexibility to rotate or bend to accommodate system motion. The manufacture of origami-based bellows is likely to be less expensive.

Use of a bellows-like device is needed within the drill chassis to protect gears, bearings, and other moving parts, as shown in Figure 3.2(b). During operation, the drill bit emerges from a hole in the baseplate of the tool as shown in Figure 3.1. The improved performance of the mechanism due to increased compressibility of the bellows is shown in Figure 3.3. An origami-based bellows enables the entire mechanism to be smaller because of its improved compressibility. A bellows with higher compressibility will allow for deeper drill penetration and increase the likelihood of mission success. Previous compliant mechanism research has demonstrated origami-based bellows capable of compression ratios exceeding 1:30, compared to 1:8 for metal bellows, making them a strong candidate in bellows design for space mechanisms [20]. Use of an origami bellows would achieve the desired compressibility while significantly reducing mass (Figure 3.4) and the parasitic reaction forces in the bellows.

\subsection{Background}

Recent research has shown possibilities for origami-based bellows design, including various origami patterns that can be modified to give predicted results $[9-11,20]$. Figure 3.5 shows the 


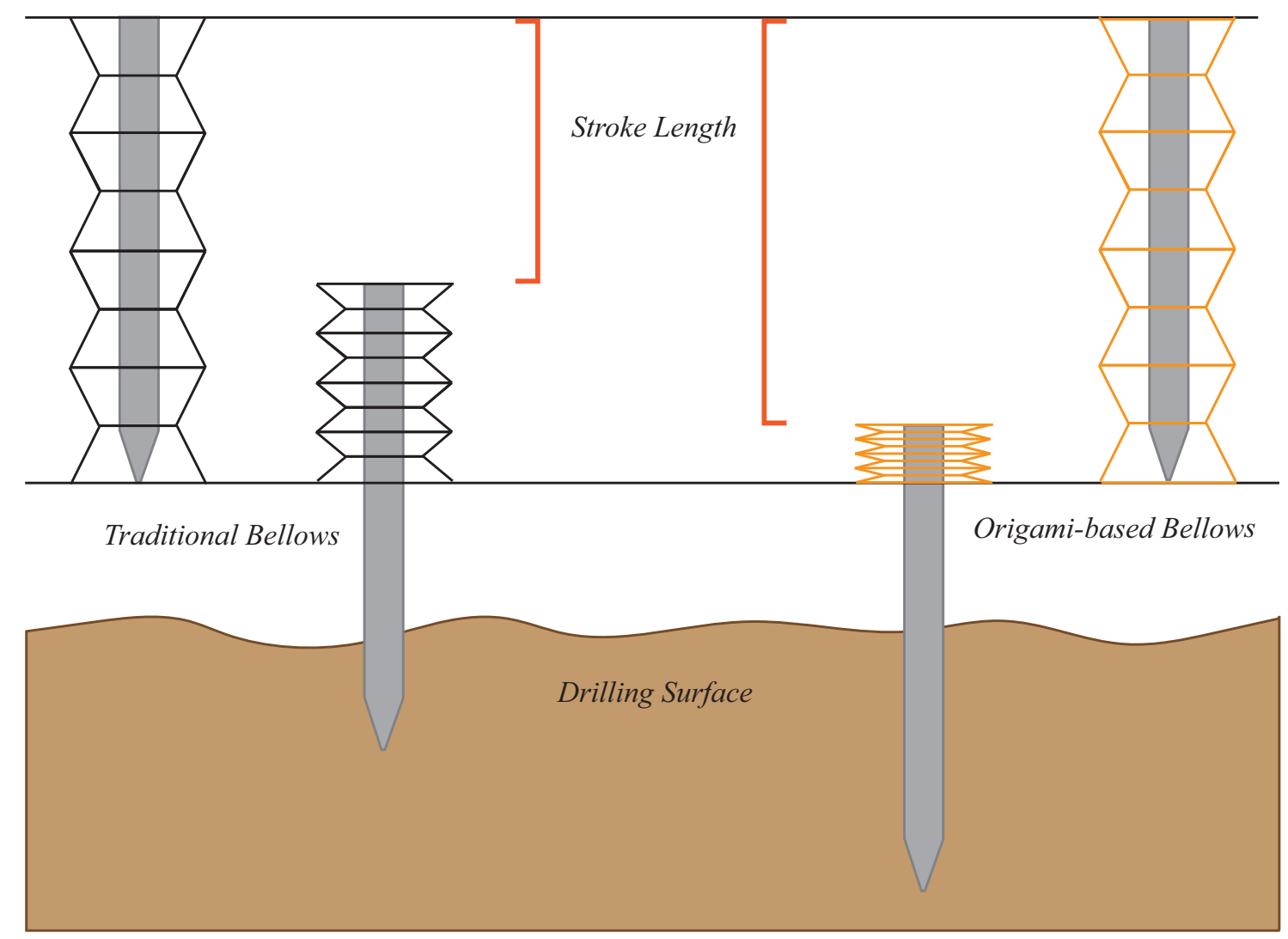

Figure 3.3: Increased compressibility allows for increased stroke length and deeper drill depth into the drilling surface.

Kresling pattern, an origami pattern adaptable to various design constraints. The Kresling pattern folds into a cylindrical shape, much like a bellows. It provides relatively high compressibility compared with other patterns but requires far fewer folds, allowing for faster fabrication by removing the number of creases required to create the cylinder.

\subsubsection{Modeling of Origami Bellows}

The Kresling-based origami bellows is designed using mathematical models defined by input parameters for the desired inner and outer diameters, stroke length, and number of sides of the bellows, resulting in output dimensions that will create a physical pattern used to fabricate a bellows. The inputs are dependent upon the spacial limitations for a specific application. Figure 3.6 demonstrates how the bellows is generally constrained by an annulus defined by an inner and outer 


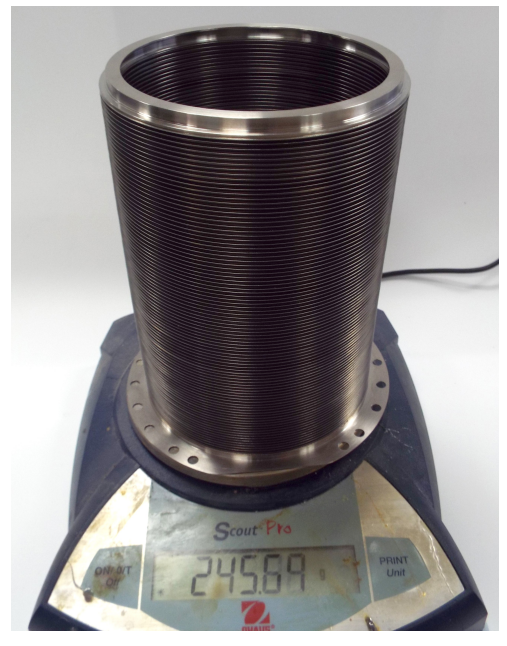

(a) Traditional metal bellows.

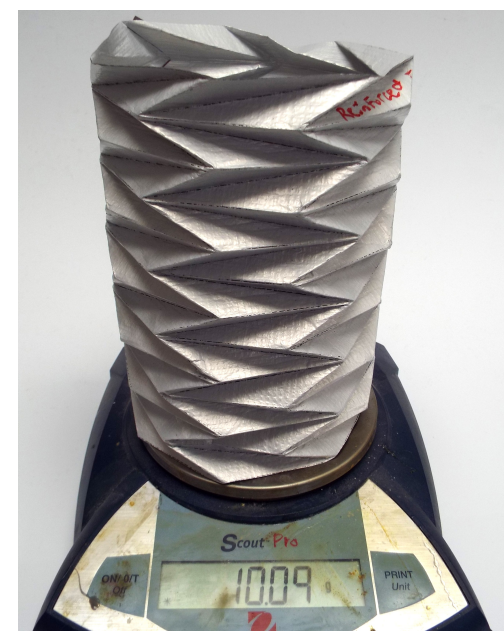

(b) Origami-based bellows.

Figure 3.4: Mass comparison of traditional metal bellows and comparable origami-based bellows.

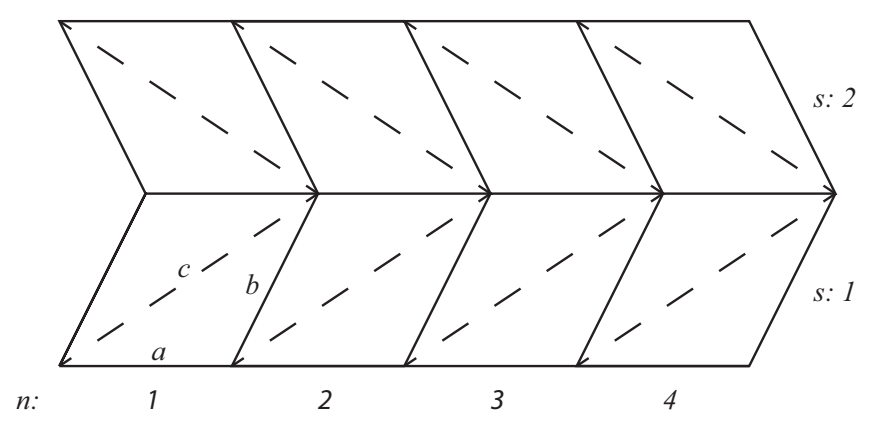

(a) 4-sided 2-story Kresling pattern with defining parameters.

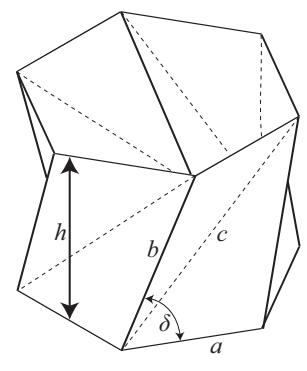

(b) 6-sided Kresling pattern folded into a single story.

Figure 3.5: Kresling pattern.

diameter. The values selected for the input parameters will dictate the amount of available rotation and the compressibility of the bellows.

Functions are used to model a Kresling-based origami bellows using the specified inputs of $D$ (outer diameter), $d$ (inner diameter), and $n$ (number of sides). Figure 3.5(a) shows the resulting dimensions for each individual tessellated unit within the bellows pattern. The functions to model one of the tessellation units shown in Figure 3.5(a) are: 


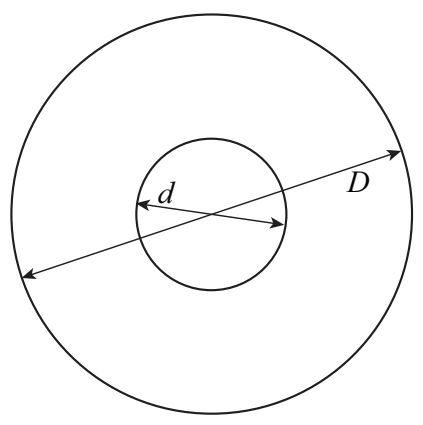

(a) Annulus defined by inner and outer diameter.

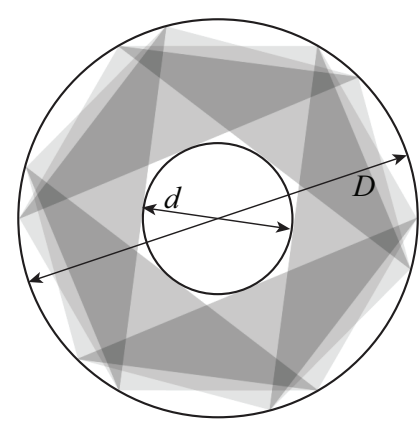

(b) Kresling-based origami bellows fitting within a specified annulus.

Figure 3.6: Annulus constraint for bellows.

$$
\begin{gathered}
a=D \sin \left(\frac{\pi}{n}\right) \\
b=D \sin \left(\arccos \left(\frac{d}{D}\right)-\frac{\pi}{n}\right) \\
c=D \sin \left(\arcsin \left(\frac{b}{D}\right)+\frac{\pi}{n}\right)
\end{gathered}
$$

where $a, b$, and $c$ are shown in Figure 3.5.

Using the results of these equations, a tessellation unit can be modeled, propagated to create a full pattern, and finally applied to fabricate the bellows.

These equations describe the bellows in a compressed state and are used to create discrete stories, $s$, in the bellows. While the inner diameter will increase as the bellows is extended, the outer diameter remains constant, thus ensuring the bellows never extends outside of the allotted annulus.

\subsubsection{Prevention of Crease Inversion}

A challenge to origami bellows modeling arises when the bellows is deployed far enough to cause buckling in the creases. If the bellows is extended too far, creases can invert, either temporarily or permanently, and cause the bellows to fail prematurely. If the over-extension is only 
slight, the crease inversion will cycle between the normal and inverted state, greatly reducing the fatigue life of the bellows. If the over-extension is significant, the crease may become permanently inverted and cause asymmetric compression. This catastrophic failure prevents the bellows from providing its intended function and most often deforms the bellows outside of the allotted annulus.

Prevention of crease inversion is done by ensuring each individual story does not deploy past a specified value. Figure 3.5(b) presents the deployment angle $\delta$, which is evaluated experimentally for given bellows parameters and materials to ensure $\delta$ remains below a specified $\delta_{\text {max }}$ to prevent crease inversion. The full extended length is then achieved by taking the deployed height of a single story, $h_{\text {deployed }}$, and observing

$$
h_{\text {deployed }}=b \sin \delta_{\text {max }}
$$

It then follows that the full extended bellows height is

$$
H=s_{\text {deployed }}
$$

\subsection{Bellows Design}

\subsubsection{Origami Designs}

The ARM utilizes a removable drill bit for drilling in the event a bit fails before successful anchoring is achieved. This requires a chuck that will rotate $30^{\circ}$ to release a failed bit, receive a new bit, and rotate again to restrain the new bit. The bellows cannot interfere with this rotation and must either avoid or comply with this motion.

The rotating drill chuck is at risk for malfunction due to debris exposure. Debris may accumulate between the rotating parts of the chuck and prevent it from fully rotating. A removed drill bit could also expose the inside of the drill chuck to floating debris and potentially prevent a new bit from successful insertion and retention. The bellows must also remain a safe distance from the spinning drill bit.

Several designs were considered in light of these requirements and are summarized in Table 3.1. 


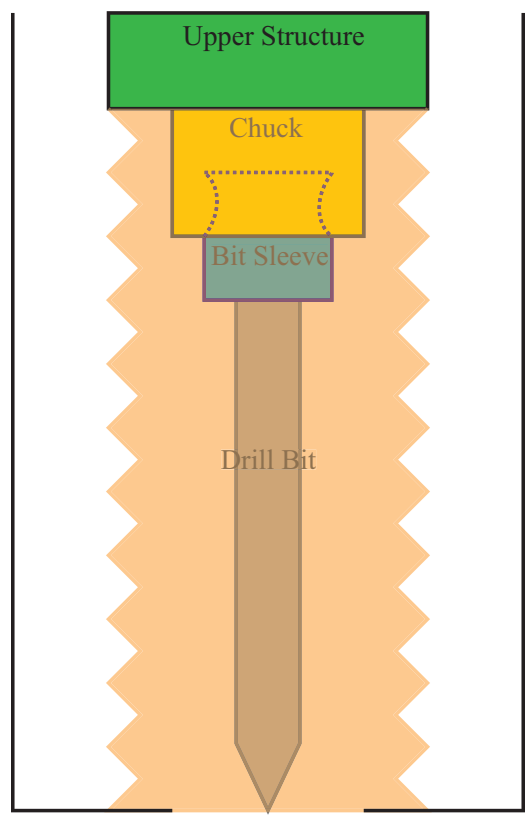

(a) Compressing Bellows

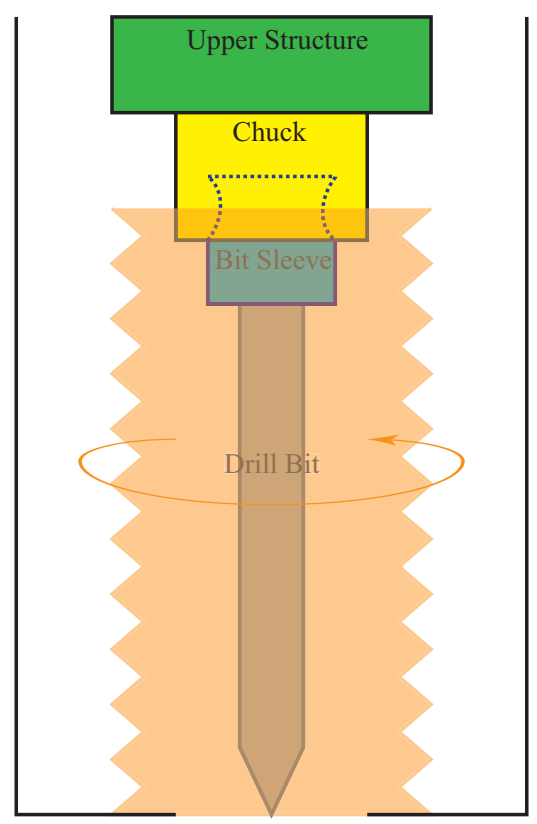

(b) Rotating Bellows

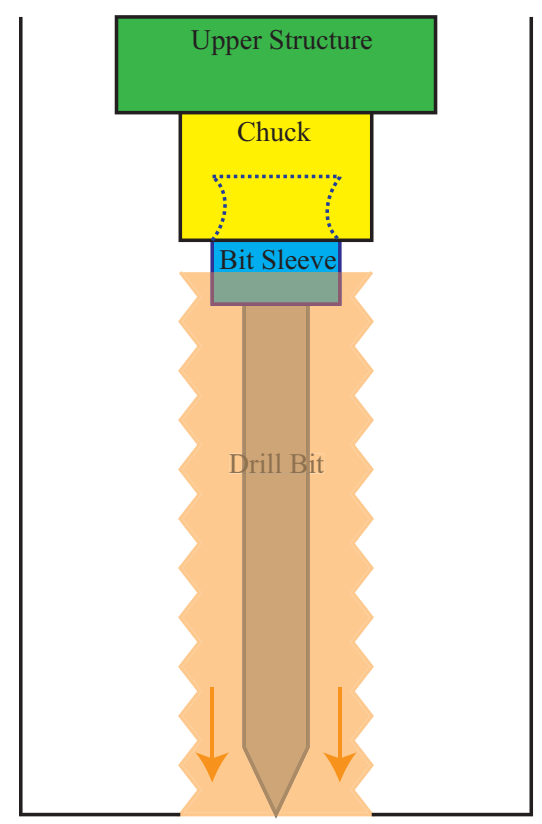

(c) Disposable Bellows

Figure 3.7: Final design concepts for origami-based bellows.

\section{Compressing Bellows}

The most straightforward design is a bellows that attaches to the structure located directly above the drill chuck. This allows for the largest possible annulus for the bellows to occupy, allowing greater deployment for each story and reducing the risk of crease inversion during deployment. It allows the bellows to maintain a greater distance from the rotating drill. It simplifies mounting and bellows design. Conversely, it exposes the chuck to drilling debris during rotation and bit removal.

\section{Rotating Bellows}

Traditional metal bellows cannot easily be designed to allow rotation about the axis of compression. The Kresling pattern is able to compress and expand through collapsing and expanding single-story origami structures. Since each of these collapsing structures rotates during motion, the entire mechanism can be designed for desired rotations at its boundaries when held at mid-stroke length. The compliant nature of the Kresling pattern could be utilized to allow a bellows to attach directly to the base of the chassis and to the drill chuck, allowing for rotation of the chuck while 


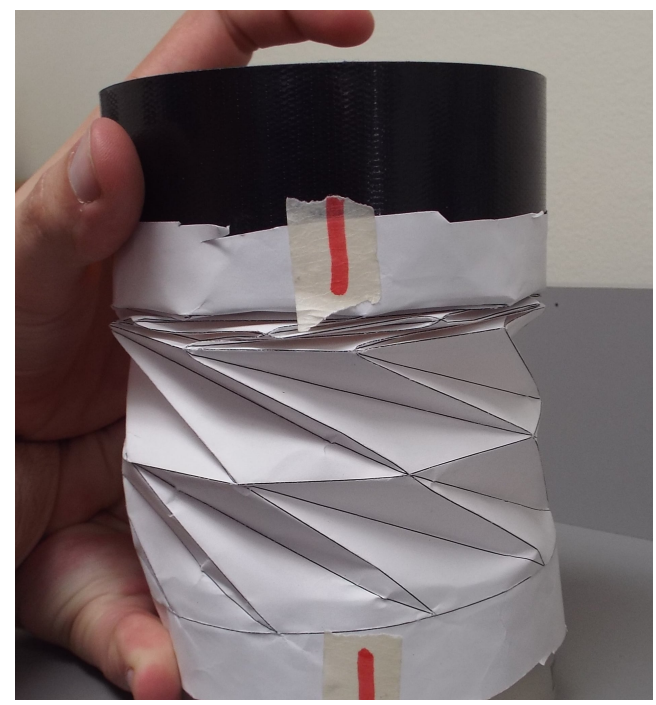

(a)

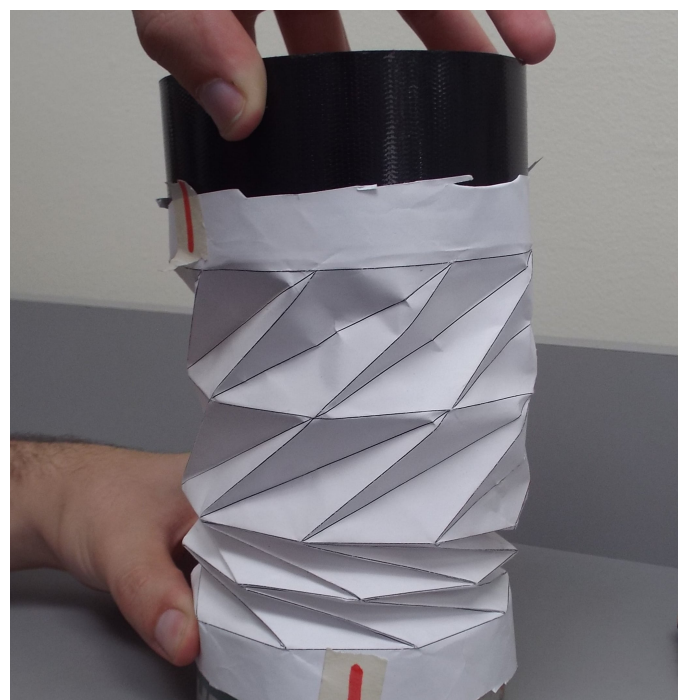

(b)

Figure 3.8: Rotation of bellows prototype using origami design.

protecting its rotating parts in addition to the other sensitive parts surrounding the drill. This would reduce part count and prevent the use of a bearing or bushing to allow this rotation.

This rotation is dependent upon the annulus area permitted by the rest of the structure. As the annulus is increased and inner diameter reduced, the amount of rotation in each story of the bellows will increase. If given insufficient space, the rotation of the bellows will be only slight and insufficient to provide the needed rotation to remove the drill bit.

\section{Disposable Bellows}

Another option includes having multiple bellows, each one living with an associated drill bit. If a bit fails, the bit and bellows would be removed from the chassis and replaced with a new set of bit and bellows. This would allow debris that has collected inside the bellows to be discarded when a failed bit is removed.

While removing current debris is highly desirable, doing so will temporarily expose highly sensitive parts within the ARM to other drifting debris. There are other additional complications, including higher part count and the need for reliable disengagement and attachment of a new bellows. 


\subsubsection{Materials}

Various materials were investigated for use in the ARM bellows, most of which were selected from a range of materials already flight-approved for NASA missions. Their known properties are not discussed here, but much can still be learned about their behaviors related to origami design and application in harsh environments.

\section{Kapton $^{\circledR}$}

A common space material, polymide $\left(\operatorname{Kapton}^{\circledR}\right)$ is easily creased and maintains crease memory well. Its resistance to radiation makes it useful for long-term application where exposure to radiation may be an issue. Kapton ${ }^{\circledR}$ has a relatively high tensile strength, but if cut or torn, the cut will easily propagate.

\section{Ultra-High Molecular-Weight Polyethylene}

Ultra-High Molecular-Weight Polyethylene (UHMWPE) is resistant to ablation, tearing, and other abuse. It maintains crease memory and is easily worked. Once torn or cut, UHMWPE is resistant to cut propagation. The material requires a large amount of yield before separation occurs. UHMWPE has a relatively low melting temperature. It is also not a commonly used material on NASA missions.

Table 3.1: Summary of key design parameters for origami-based bellows.

\begin{tabular}{lcccc}
\hline & $\begin{array}{c}\text { Risk of Inner } \\
\text { Chassis } \\
\text { Contamination }\end{array}$ & $\begin{array}{c}\text { Risk of Inner } \\
\text { Chuck } \\
\text { Contamination }\end{array}$ & $\begin{array}{c}\text { Risk of Chuck } \\
\text { Rotation } \\
\text { Contamination }\end{array}$ & $\begin{array}{c}\text { Complexity } \\
\text { and Part Count }\end{array}$ \\
\hline Compressing Bellows & Low & Mid & Mid & Low \\
\hline Rotating Bellows & Low & Mid & Low & Low \\
\hline Disposable Bellows & High & Low & Low & High \\
\hline
\end{tabular}




\section{Tedlar $^{\circledR}$}

Double-laminate fiber-reinforced polyvinyl fluoride $\left(\right.$ Tedlar $\left.^{\circledR}\right)$ is easily creased, does not propagate cuts, and maintains crease memory well. Though it is not as robust as UHMWPE, it has been used in many flights. It provides low reaction forces when compressed or extended. It is less stiff than the other materials considered, making the panels created in origami folding more prone to flexure and bending. This will reduce the axial stiffness, making actuation of the bellows easier, but also reduces the lateral stiffness, making the bellows more prone to buckling.

\section{$\operatorname{Vectran}^{\circledR}$}

A fiber spun from an aromatic polyester, $\operatorname{Vectran}^{\circledR}$ is a woven fiber from a liquid crystal polymer. It will hold a crease well when heat treated and does not have its properties altered by the heating process. Vectran ${ }^{\circledR}$ has low resistance to UV exposure. It is strong and does not propagate cuts. Its stiffness is low, making creases relatively easy to invert.

\section{Beta Cloth}

Beta cloth is commonly used in the outer layers of space suits. Though it is very robust, Beta cloth is hard to crease and has poor crease memory.

\subsubsection{Seam Closure}

Perhaps the greatest challenge to origami bellows design is illustrated in Figure 3.9. When fabricated from a single sheet, the material is curved to a cylinder and sealed at the seam to create the bellows. This requires the seam to both maintain integrity through its expected actuation life as well as perform well under expected environmental conditions.

While other methods for fabricating a bellows without the need of a seam are currently under development, this work requires seam closure from single-sheet fabrication. Several options were considered and are presented below. 


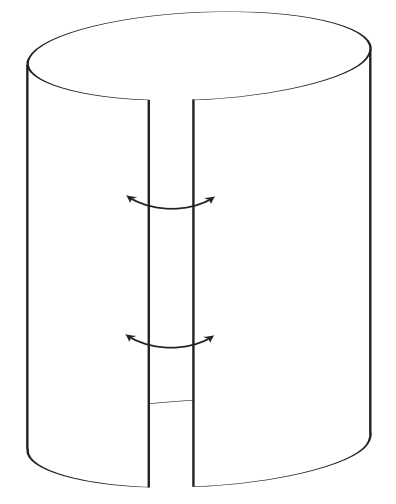

Figure 3.9: Creating and maintaining an adequate seal is a challenge for origami bellows design.

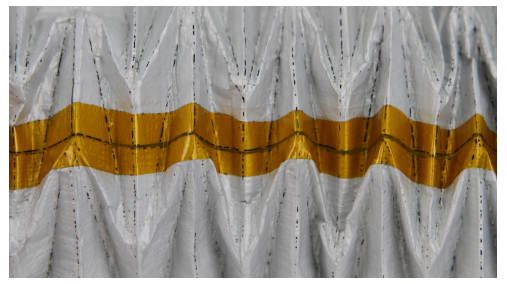

(a) Seam edges placed adjacently and taped.

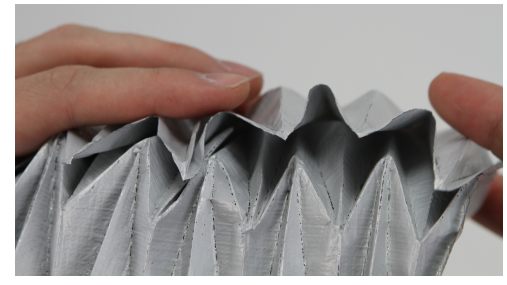

(b) Seam edges overlapped then sealed.

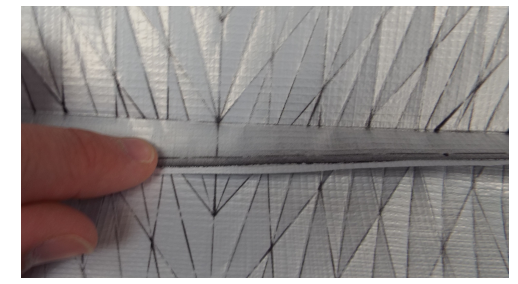

(c) Seam edges overlapped and flanged outward.

Figure 3.10: Various configurations for possible seam closure.

\section{Tapes and Adhesives}

Adhesives prove to be the simplest option for seam closure. Under standard conditions, many adhesives are flexible, bond well, are easily applied, and have good fatigue life. Difficulties arise when environmental conditions become extreme since not all adhesives are meant for high strain. Poor performance is exacerbated most notably when temperatures drop below the rated temperature of the adhesive.

Several adhesives were considered for application. Figure 3.10(a) demonstrates how use of a tape allows for seam closure without the need to overlap any layers of material. Kapton ${ }^{\circledR}$ tape with a silicon adhesive backing bonds well at a large range of temperatures and with a variety of materials, including Tedlar ${ }^{\circledR}$. It has demonstrated performance in field applications ranging from $-269^{\circ} \mathrm{C}$ and as high as $260^{\circ} \mathrm{C}$ [24]. 
Other adhesives considered were $3 \mathrm{M}^{\prime}$ 's $\mathrm{Y} 966^{\mathrm{TM}}$ and $\mathrm{VHB}^{\mathrm{TM}}$ adhesives. These adhesives will require an overlap at the bellows seam as demonstrated in Figures 3.10(b) and 3.10(c).

\section{Stitching}

Another method to close the bellows seam is to stitch the edge using a high-strength thread. Stitching would remove the ambiguity surrounding adhesive bonding in any temperature and ensure the bellows is always held together properly.

Drawbacks include perforating the material and causing the bellows to be asymmetric. Stitching the seam creates small perforations that could potentially allow small debris to pass through and collect on sensitive parts within the ARM. Asymmetry will also cause one side of the bellows to be stiffer than any other side. This could effect compression and behavior.

Depending on the required life of the parts being protected, stitching may be an acceptable option even considering the perforations allowing debris to pass through the bellows. If the life of the mechanism is low, such as for the ARM drill, allowing small debris to pass through the holes created by stitching will have little impact on the performance of the mechanism. The bellows can also be designed to have multiple stitches to help balance the stiffness to more accurately manage the bellows behavior.

\subsection{Design Selection}

\subsubsection{Origami Design Selection}

Table 3.1 summarizes key design parameters for each bellows option. While the disposable bellows is beneficial for minimizing contaminants in and around the chuck, the potential risk of debris drifting within the chassis is too great for further investigation. Its features would be more appropriate for applications involving lower risk of inner contamination or where gravity could be a greater influence in controlling drifting debris.

The rotating bellows demonstrates great promise for use and prototypes performed well. However, the annulus limitations within the ARM restrict the bellows from achieving sufficient rotation $\left(30^{\circ}\right)$ for bit removal. Due to these limitations, a traditional compressing bellows was se- 


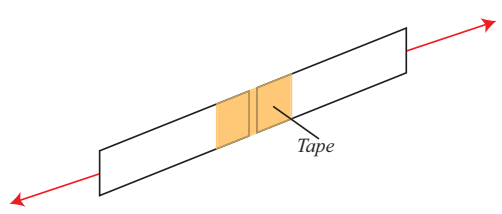

(a) Adjacent strips bonded with tape under tensile seam separation.

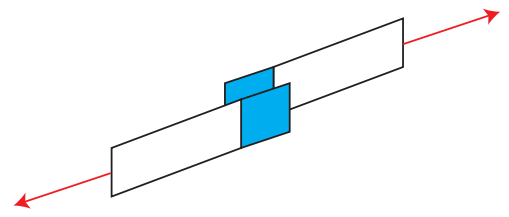

(b) Overlapping seam under tensile seam separation.

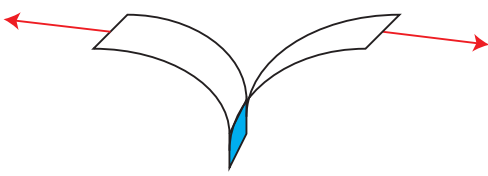

(c) Overlapping seam under peeling seam separation.

Figure 3.11: Different testing configurations for testing seam closure design. Blue regions represent bonded areas.

lected for use within the chassis of the ARM. It provides permanent protection of sensitive parts from debris while maintaining simple and permanent mounting to the chassis. The chuck is designed to meet its requirements in the presence of the small amount of debris that may contaminate the surfaces after an aborted drill bit is released.

\subsubsection{Material Selection}

Tedlar $^{\circledR}$ was selected for use in the ARM bellows. Though it does not have high resistance to radiation, it will be housed withing a metal chassis that will shield it from the most damaging radiation. The bellows may be exposed to high-velocity debris, thus leading to Kapton ${ }^{\circledR}$ being rejected because of its tendency to propagate cuts. UHMWPE is not currently approved for flight on NASA missions and has a high outgassing rate. Tedlar's ${ }^{\circledR}$ low axial stiffness make it an ideal candidate for use. The lateral stiffness can be accomodated by providing the origami bellows design with sufficient stories, $s$, to prevent excessive extension of any singular story.

\subsubsection{Seam Testing and Selection}

Tapes and adhesives were tested for their efficacy by bonding two sample coupons of material and putting them in different testing configurations to test their bond at low temperatures. Expected temperatures for the ARM are above $-150^{\circ} \mathrm{C}$. These samples were placed in liquid nitrogen $\left(-196^{\circ} \mathrm{C}\right)$, allowed to reach equilibrium, removed, and then immediately placed under a tensile load. Tests were done using Tedlar $^{\circledR}$ as the coupon material and the selected adhesives and tapes to bond the samples. 
All tapes and adhesives were effective in seam closure at room temperature but were unable to maintain a bond with Tedlar $^{\circledR}$ at liquid nitrogen temperature $\left(-196^{\circ} \mathrm{C}\right)$. Ten samples of each adhesive were tested. All samples failed to reach a $5 N$ load before failure.

Coupon testing for a stitched design was performed using the configurations demonstrated in Figures 3.11(b) and 3.11(c). Testing showed no significant difference between performance at room temperature and at liquid nitrogen temperature. Due to its permanence regardless of temperature, the ARM bellows was stitched using a Kevlar ${ }^{\circledR}$ thread. The stitch length was maximized to reduce the number of perforations created in the Tedlar $^{\circledR}$.

\subsubsection{Selected Design}

Figure 3.12(a) shows the selected design for the origami bellows. It is secured within two aluminum mounting plates for attachment to the ARM microspine tool. The pattern is designed to fill the maximum annulus available within the drill chassis to reduce the number of stories necessary to reach full stroke length. Additionally, the number of sides on the bellows is $n=9$ based on recommendations in previous work [10].

The stitch used to close the seam of the bellows is shown in Figure 3.12(b). The stitch uses

a Kevlar ${ }^{\circledR}$ thread and has maximized the distance between perforations to reduce the chance of debris accessing the inner chassis. Increased perforations also result in lower tensile loads before failure.

\subsection{Fabrication of Origami Bellows}

\subsubsection{Creasing}

Origami bellows were manufactured by printing a fold pattern onto a sheet of fabrication material. The fold pattern is hand-creased to create the desired bellows shape. Challenges with creasing the bellows using other methods arise when using a single planar sheet to create a cylindrical object that requires a seam for closure. Recent research has shown promise in creasing and fabrication methods of origami, including vacuum forming the pattern into a mold or using a device able to crease both mountain and valley folds into a single sheet $[25,26]$. Increased precision 


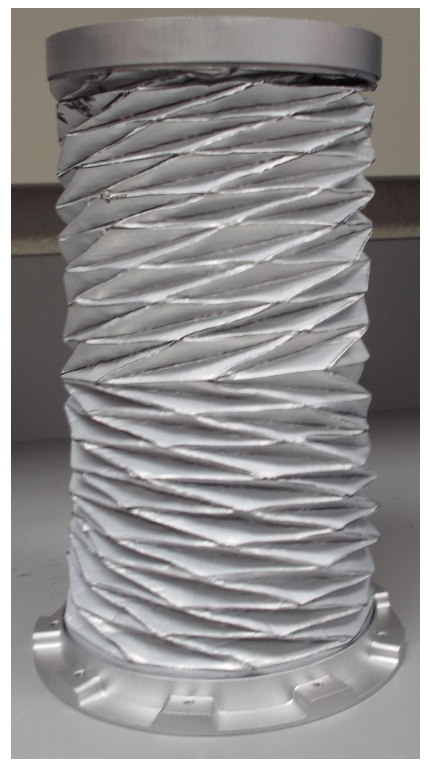

(a) A full sized bellows epoxied within aluminum mounting plates.

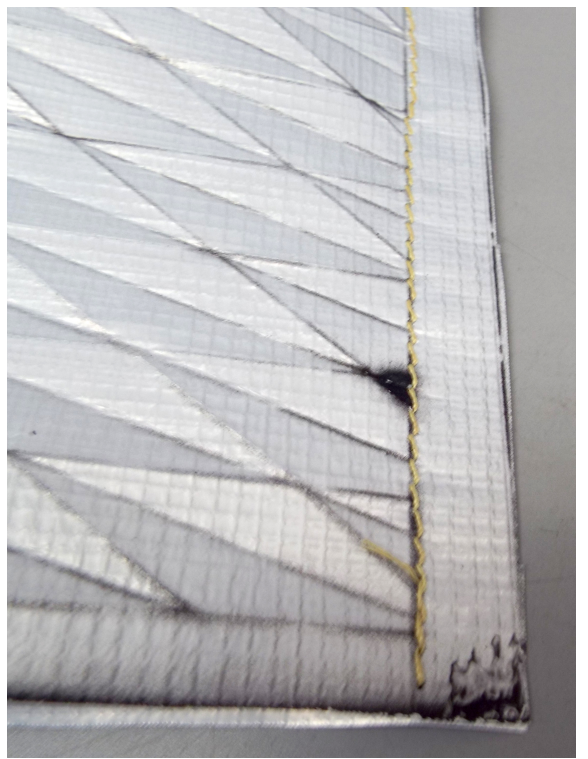

(b) A Kevlar ${ }^{\circledR}$ stitch along the seam of the bellows provides sufficient seam closure for expected temperatures.

Figure 3.12: Final bellows for ARM application.

in the fold pattern would increase the life of the bellows, prevent unwanted crease buckling, and enable the bellows behavior to more closely match that predicted by the model.

\subsubsection{Epoxy Testing and Selection for Mounting}

Figure 3.13 shows how the bellows is mounted to the drill chassis. A short tab is left at the ends of the bellows and inserted into a circular slotted plate. Epoxy is used to hold the bellows in the slot and seal gaps. The plate is then bolted to the drill chassis.

It was unclear if the epoxy would be able to hold under expected environmental conditions. Tedlar $^{\circledR}$ samples were bonded to aluminum using both $3 \mathrm{M}$ Scotch-Weld $2216^{\mathrm{TM}}$ and Loctite ${ }_{\circledast}$ EA 9394 (Figure 3.14) and allowed to cure before temperature testing.

During testing, the samples were allowed to reach equilibrium in liquid nitrogen then immediately placed under a tensile load. Results are shown in Figure 3.15. It is shown that the mean difference in tensile strength using both epoxies was not statistically significant. Failure never oc- 


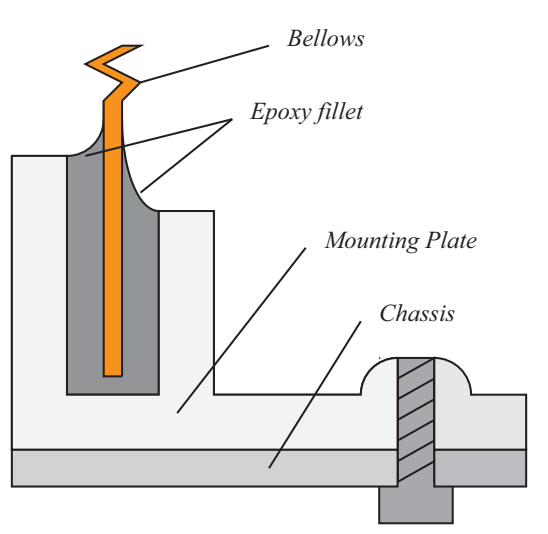

(a) A tab on the end of the bellows is epoxied within a slot. The epoxy forms a fillet to reduce stress concentrations.

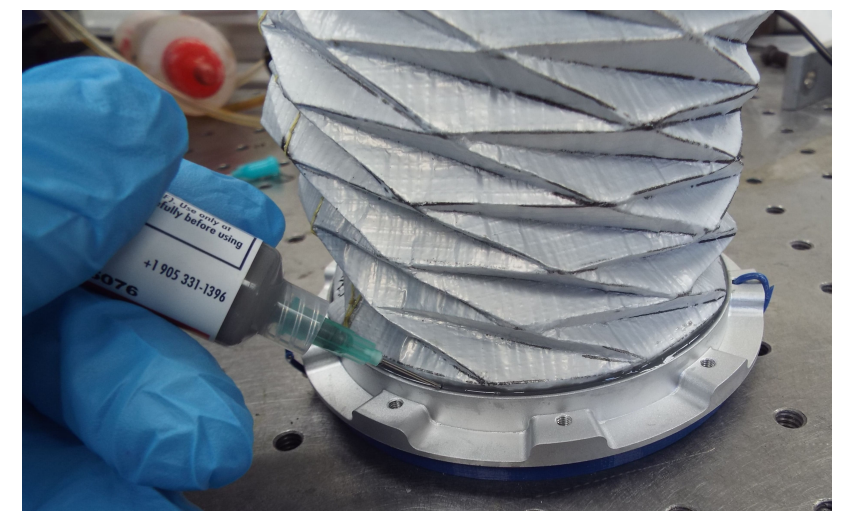

(b) Epoxy being applied to bellows and mount.

Figure 3.13: Bellows mounted within aluminum slotted plate.

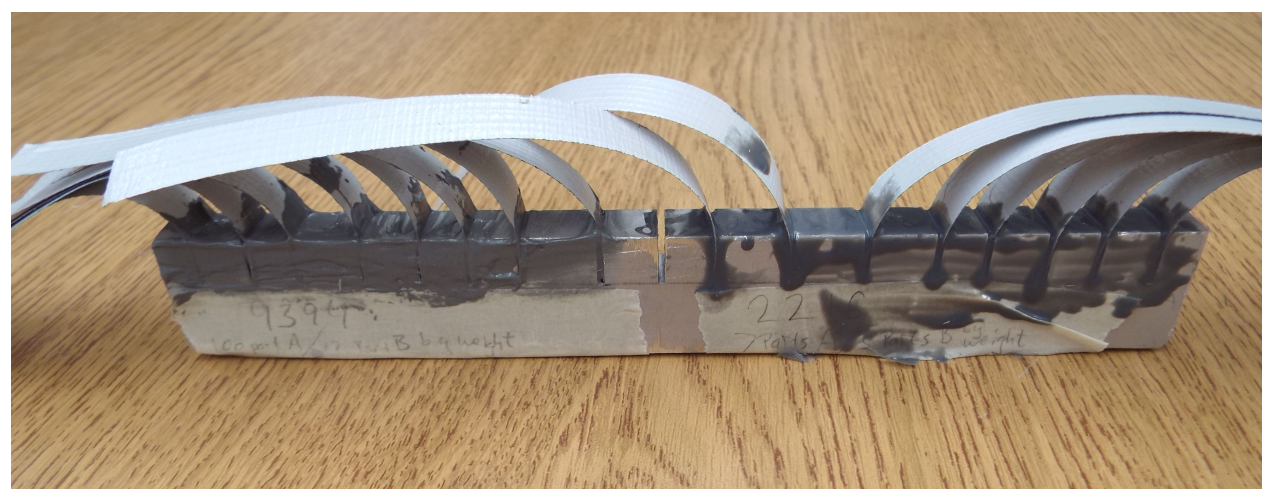

Figure 3.14: Tedlar $^{\circledR}$ samples bonded to aluminum using various epoxies.

cured at the bond. Rather, all failures occured in the test coupon, allowing the use of either epoxy for mounting.

The test samples failed first at the edge of the test coupon, shown in Figure 3.16. Stress concentrations likely led to the failure location. It can be concluded that failure is most likely to occur in the material before failure occurs in the epoxy. While both epoxies performed well, 3M Scotch-Weld $2216^{\mathrm{TM}}$ was selected for its low viscosity, making it able to more easily fill the small gap created by the mounting plate. Additionally, these results led to creating the fillets in the epoxy shown in Figure 3.13(a) during the bonding fabrication for mounting. 


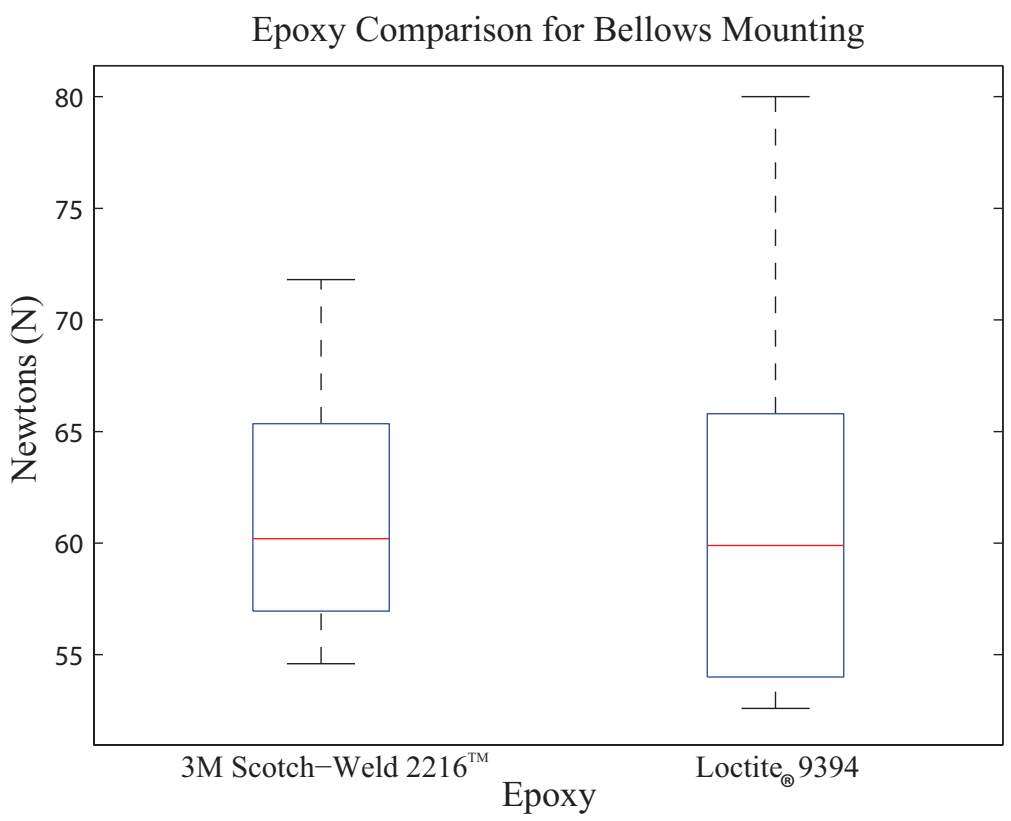

Figure 3.15: Load at failure in $\operatorname{Tedlar}^{\circledR}$ using different epoxies to bond to aluminum. Samples were tested at $-196^{\circ} \mathrm{C}$.

It should be noted that the design of the bellows creates an $n$-sided polygon per story. The mounting plate for the bellows has a slot for bellows insertion in a circle of constant radius. While the bellows will be slightly deformed when placing the polygon shape into the slots, the deformation is negligible since $n$ is relatively large. For smaller $n$ values, the mounting plate should be modified to reduce deformation.

\subsection{Environmental Testing}

\subsubsection{Temperature}

Figure 3.17 demonstrates initial bellows performance testing for expected environmental temperatures. The full-length bellows was placed in a cold chamber and driven over its full stroke length using a linear actuator. The testing temperature was initially placed at $-50^{\circ} \mathrm{C}$ and the bellows was compressed and expanded 50 times, whereupon the bellows was inspected for failure. The temperature was then lowered to $-80^{\circ} \mathrm{C}$ and again cycled 50 times before secondary inspection. 


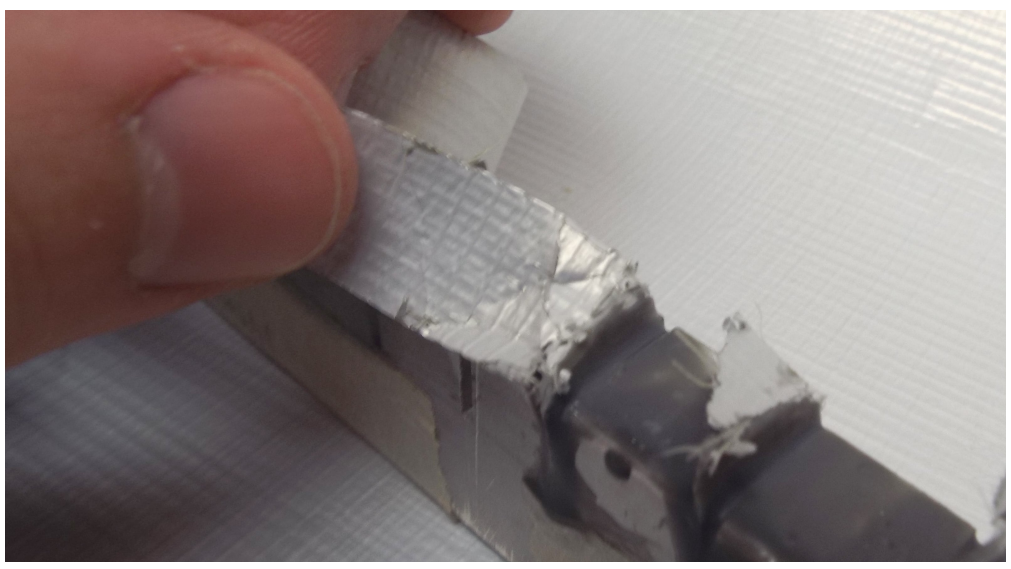

Figure 3.16: Tedlar $^{\circledR}$ samples tested to failure failed at corners where stress concentrations were greatest.

The bellows performed as expected during initial cycling. Figure 3.17(b) shows the results of testing at $-80^{\circ} \mathrm{C}$. At this temperature, the bellows began to buckle under a compressive load. The side of the bellows that buckled inwards was directly opposite the stitched seam. The most likely cause of this behavior would derive from asymmetric compression. The stiffness within the bellows is slightly greater along the seam. While this stiffness difference is low at room temperature, the material response to changing temperatures augments the difference in stiffness, eventually causing the bellows to buckle during compression.

Tests were repeated with a second bellows. In these tests, the outer seam was trimmed to be much tighter to the outer annulus. The stroke length was shortened by several $\mathrm{mm}$ to reduce the risk of crease inversion. Tests were run similarly to the first trials but with no observed deformation.

\subsubsection{Drilling}

Figure 3.18 shows the prototype bellows mounted to the Microspine Tool for full-model drill testing at room temperature. After several months of drill testing, no observable failure has been identified. The bellows has demonstrated no signs of fatigue failure and remains fully intact around the epoxy. The stitched-seam has showed no signs of failure or propagation of perforations. Additionally, debris has been adequately contained as predicted. 


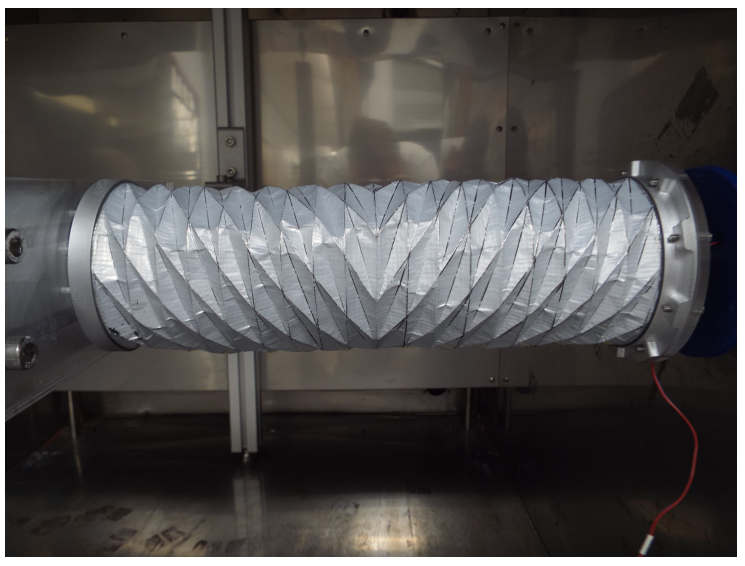

(a)

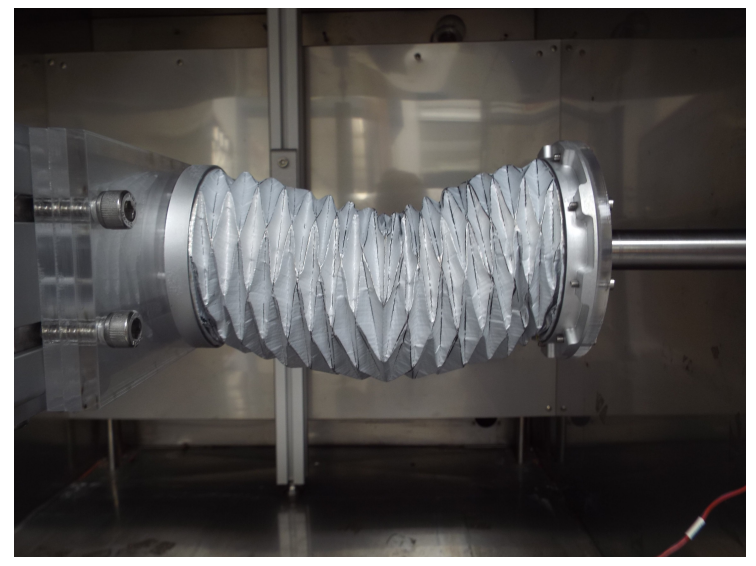

(b)

Figure 3.17: Asymmetric compression after repeated cycling at $-80^{\circ} \mathrm{C}$.

\subsection{Conclusion}

Highly compressible origami bellows have demonstrated advantages for use in NASA's Asteroid Redirect Mission, as summarized in Table 3.2. A Tedlar ${ }^{\circledR}$ based bellows with a Kevlar ${ }^{\circledR}$ stitched seam is well suited for debris containment in space conditions. Tedlar ${ }^{\circledR}$ was selected for its crease memory, resilience, and demonstrated use in past flights. 3M Scotch-Weld $2216^{\mathrm{TM}}$ epoxy was able to maintain an adequate bond with Tedlar ${ }^{\circledR}$ below expected environmental temperature. A permanent origami bellows provides the needed compressibility while meeting spacial restrictions of the ARM drill.

The current design consisting of a single stitch for seam closure can be improved for highcycle applications. Possible solutions would include using a pseudostitch along the edge of the bellows opposite the seam to increase stiffness and symmetry during compression. Other solutions will come through future development to remove the need for a seam.

Table 3.2: Summary of traditional and origami-based bellows features.

\begin{tabular}{lcccc}
\hline & $\begin{array}{c}\text { Compression } \\
\text { Ratio (best) }\end{array}$ & Mass & $\begin{array}{c}\text { Compression } \\
\text { Force }\end{array}$ & $\begin{array}{c}\text { Performance in } \\
\text { Harsh Conditions }\end{array}$ \\
\hline Traditional Metal Bellows & $1: 8$ & & & Satisfactory \\
Origami-based Bellows & $1: 30$ & Reduced & Reduced & Satisfactory \\
\hline
\end{tabular}




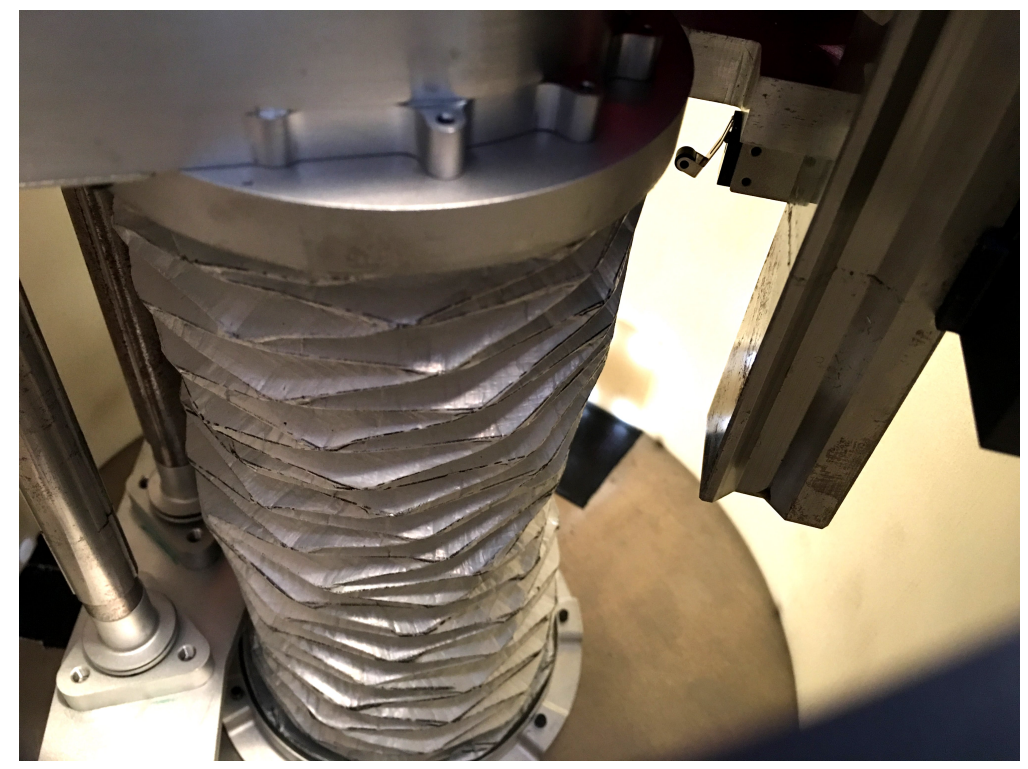

Figure 3.18: Prototype origami-based bellows mounted within Microspine tool.

The Kresling pattern is adaptable to many different design requirements. Origami enables a much greater compression ratio for origami bellows in comparison to a comparable metal bellows. The use of an origami bellows provides major benefits over metal bellows in compression and possible motion.

The Asteroid Redirect Mission drill is only one example of origami bellows space applications. Origami bellows can be adapted through material selection and crease design to suit a variety of design needs. Origami bellows show great promise in space applications such as shaft protection, deployment mechanisms, supports, or protective barriers. 


\section{CHAPTER 4. CONCLUSION}

\subsection{Conclusion}

This work provides an alternative design method to develop origami-based bellows that outperform traditional metal options. Origami bellows are capable of providing adequate shielding to sensitive spacecraft parts under the conditions observed in this work. Traditional metal shielding can be reliably replaced with origami-based shielding for Martian and asteroid-bound applications. However, the harsh conditions evaluated in this work can be found in many other applications, broadening the potential reach of origami-based bellows.

The origami pattern vetting process introduced in Chapter 2 provides several options for origami-based bellows patterns. While the Kresling pattern was selected for use in this work, other patterns exhibited behavior that may be preferred in other conditions that require no rotation or demand rigid-foldability of the structure. Many materials may be used in bellows design and should be selected to meet the expected environmental conditions.

Origami-based bellows offer $96 \%$ mass reduction over traditional bellows. With the high cost of space flight, this mass reduction can reduce flight expenses. The 1:30 compression ratios achieved by origami bellows have proven to be advantageous over the 1:8 ratios achievable in traditional bellows. The reduced stowed height of origami-bellows allows for mechanism size reductions, directly resulting in reduced mass and cost.

The manufacture of origami-based bellows is a challenge, especially for applications requiring no debris penetration through the bellows. The creasing of origami-based bellows can potentially be automated to increase precision, but seam closure remains a challenge under extreme thermal conditions.

Increased flexibility in origami-based bellows may provide additional shielding opportunities outside the capacities of traditional metal bellows. Applications that demand shielding on 
flexible, curved, or rotating parts can utilize this work to produce adequate shielding designed to meet these constraints.

The design methods created in this work provide a framework for bellows design to create an origami-based tube adapted to the constraints of specific applications. While this work is focused on origami-based bellows design for space, its results can be translated into other industrial or terrestrial applications.

\subsection{Future Work}

Future work could be accomplished by exploring solutions to challenges faced and by investigating alternative designs not selected for the applications discussed in Chapters 2 and 3.

Seam closure continues to be a challenge to origami-based bellows. Taping the seam together is a solution appropriate for few space-based applications, the low temperatures of most space systems driving the need for alternative solutions. A stitched seam allows for fine debris to drift through the bellows, making this solution inappropriate for systems requiring $100 \%$ containment. Future work could investigate alternative approaches to seam closure, such as sonic welding or thermo-forming bellows to remove the need for a seam.

Chapter 3 highlighted the buckling tendency of the bellows when the axial stiffness of the bellows was not uniform. Addressing this behavior would improve the reliability of the bellows under extreme conditions. A bellows could be designed to remain in constant tension to remove the tendency to buckle.

Origami bellows are currently folded by hand. While the crease patterns on the material are precise, the human error in folding bellows leads to failure points or locations where the creases will invert over time. Methods to fold a bellows that is independent of human error would greatly improve the performance of the bellows.

Bellows were designed in Chapter 3 that allow a specified amount of rotation to allow for chuck removal on the ARM. This single application design was effective but the process of designing bellows to allow for a specified rotation was not pursued as part of this work. Development of such methods could provide designers valuable tools to customize origami-based bellows for different applications. 
Origami-based bellows provide many opportunities for future work and research to make these methods available to all designers. 


\section{REFERENCES}

[1] Howell, L. L., 2001. Compliant mechanisms. John Wiley \& Sons. 4, 23

[2] Fowler, R., Howell, L., and Magleby, S., 2011. "Compliant space mechanisms: a new frontier for compliant mechanisms." Mech. Sci, 2(2), pp. 205-215. 4, 23

[3] Zirbel, S. A., Lang, R. J., Thomson, M. W., Sigel, D. A., Walkemeyer, P. E., Trease, B. P., Magleby, S. P., and Howell, L. L., 2013. "Accommodating thickness in origami-based deployable arrays." Journal of Mechanical Design, 135(11), p. 111005. 4, 23

[4] Sigel, D., Thomson, M., Webb, D., Willis, P., Lisman, P., and Trease, B., 2014. “Application of origami in the starshade spacecraft optical blanket design." In ASME IDETC Design Conference, . 4, 23

[5] Reynolds, W. D., Jeon, S. K., Banik, J. A., and Murphey, T. W., 2013. "Advanced folding approaches for deployable spacecraft payloads." In DETC. 4, 23

[6] Katsumata, N., Natori, M., and Yamakawa, H., 2011. "Folding and deployment analyses of inflatable structures." In The 28th International Symposium on Space Technology and Science. Okinawa, Japan. 4

[7] Lang, R. J., 2008. "From flapping birds to space telescopes: the modern science of origami." In Proceedings of the 6th international symposium on Non-photorealistic animation and rendering. 5, 23

[8] Schenk, M., Viquerat, A., Seffen, K., and Guest, S., 2014. "Review of inflatable booms for deployable space structures: Packing and rigidization.” Journal of Spacecraft and Rockets. 5, 23

[9] Wilson, L., Pellegrino, S., and Danner, R., 2013. "Origami sunshield concepts for space telescopes." AIAA Paper(2013-1594). 5, 7, 23, 25

[10] Cai, J., Deng, X., Zhou, Y., Feng, J., and Tu, Y., 2015. "Bistable behavior of the cylindrical origami structure with kresling pattern.” Journal of Mechanical Design, 137(6), p. 061406. $9,10,25,37$

[11] Cai, J., Deng, X., Feng, J., and Zhou, Y., 2015. "Geometric design and mechanical behavior of a deployable cylinder with miura origami." Smart Materials and Structures, 24(12), p. $125031.10,25$

[12] Sheet, N. F., 1988. Viking mission to mars. 17

[13] http://quest.nasa.gov/aero/planetary/mars.html, 2015. Mars Facts. 17 
[14] Claudin, P., and Andreotti, B., 2006. "A scaling law for aeolian dunes on mars, venus, earth, and for subaqueous ripples." Earth and Planetary Science Letters, 252(1), pp. 30-44. 17

[15] http://curiosityrover.com/rems/uv.php, 2015. PDS REMS ENVRDR data UV irradiance. 18

[16] NASA, 1970. NASA Space Vehicle Design Criteria: Nuclear and Space Radiation Effects on Materials. NASA. 18

[17] Cummings, C. S., Lucas, E. M., Marro, J. A., Kieu, T. M., and DesJardins, J. D., 2011. "The effects of proton radiation on uhmwpe material properties for space flight and medical applications." Advances in Space Research, 48(10), pp. 1572-1577. 18

[18] Ishizawa, J., and Mori, K., 2009. "Space environment effects on cross-linked etfe polymer." Proceedings of the 11th ISMSE: on CD-ROM. 19

[19] Katsumata, N., Natori, M. C., and Yamakawa, H., 2011. "Folding and deployment analyses of inflatable structures." In The 28th International Symposium on Space Technology and Science, no. 2011-c-38. 23

[20] Butler, J., Morgan, J., Pehrson, N., Tolman, K., Bateman, T., Magleby, S. P., and Howell, L. L., 2016. "Highly compressible origami bellows for harsh environments." In ASME 2016 International Design Engineering Technical Conferences and Computers and Information in Engineering Conference. 23, 25

[21] Mazanek, D. D., Reeves, D. M., Abell, P. A., Asphaug, E., Abreu, N. M., Bell, J. F., Bottke, W. F., Britt, D. T., Campins, H., Chodas, P. W., et al., 2016. "Asteroid redirect mission (arm) formulation assessment and support team (fast) final report.". 23

[22] Parness, A., 2011. "Anchoring foot mechanisms for sampling and mobility in microgravity." In Robotics and Automation (ICRA), 2011 IEEE International Conference on, IEEE, pp. 6596-6599. 25

[23] Parness, A., Willig, A., Berg, A., Shekels, M., Arutyunov, V., Dandino, C., and Kennedy, B. "A microspine tool: Grabbing and anchoring to boulders on the asteroid redirect mission." In 2017 IEEE Aerospace Conference, Yellowstone Conference Center in Big Sky, Montana (unpublished). 25

[24] 5 Mil Kapton Tapes Technical Datasheet https://www.kaptontape.com/5_Mil_Kapton_ Tapes_Datasheet.php Accessed: 2017-01-04. 34

[25] Wang, H., Guo, C., Li, Y., Liu, Y., Wang, M., You, Z., and Zhao, D., 2016. "Structural design and forming method of single-curved surface structure based on miura-origami." In ASME 2016 International Design Engineering Technical Conferences and Computers and Information in Engineering Conference. 37

[26] Romero, J., Diago, L., Shinoda, J., Nara, C., and Hagiwara, I., 2016. "Norigami folding machines for complex 3d shapes." In ASME 2016 International Design Engineering Technical Conferences and Computers and Information in Engineering Conference. 37 